\title{
Rescaling-contraction with a lower cost technology when revenue declines
}

DOI:

10.1016/j.ejor.2019.02.037

Document Version

Accepted author manuscript

Link to publication record in Manchester Research Explorer

\section{Citation for published version (APA):}

Adkins, R., \& Paxson, D. (2019). Rescaling-contraction with a lower cost technology when revenue declines.

European Journal of Operational Research. https://doi.org/10.1016/j.ejor.2019.02.037

\section{Published in:}

European Journal of Operational Research

\section{Citing this paper}

Please note that where the full-text provided on Manchester Research Explorer is the Author Accepted Manuscript or Proof version this may differ from the final Published version. If citing, it is advised that you check and use the publisher's definitive version.

\section{General rights}

Copyright and moral rights for the publications made accessible in the Research Explorer are retained by the authors and/or other copyright owners and it is a condition of accessing publications that users recognise and abide by the legal requirements associated with these rights.

\section{Takedown policy}

If you believe that this document breaches copyright please refer to the University of Manchester's Takedown Procedures [http://man.ac.uk/04Y6Bo] or contact uml.scholarlycommunications@manchester.ac.uk providing relevant details, so we can investigate your claim.

\section{OPEN ACCESS}




\section{Accepted Manuscript}

Rescaling-contraction with a lower cost technology when revenue declines

Roger Adkins, Dean Paxson

PII:

DOI:

Reference:

$$
\text { S0377-2217(19)30185-7 }
$$

https://doi.org/10.1016/j.ejor.2019.02.037

EOR 15684

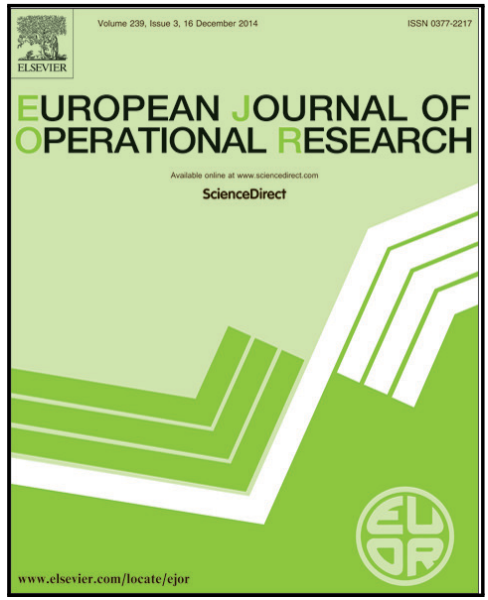

To appear in:

European Journal of Operational Research

Received date:

2 August 2017

Accepted date:

18 February 2019

Please cite this article as: Roger Adkins, Dean Paxson, Rescaling-contraction with a lower cost technology when revenue declines, European Journal of Operational Research (2019), doi: https://doi.org/10.1016/j.ejor.2019.02.037

This is a PDF file of an unedited manuscript that has been accepted for publication. As a service to our customers we are providing this early version of the manuscript. The manuscript will undergo copyediting, typesetting, and review of the resulting proof before it is published in its final form. Please note that during the production process errors may be discovered which could affect the content, and all legal disclaimers that apply to the journal pertain. 


\section{Highlights}

- Analytical solution for some rescaling-contraction options.

- Application to mature oilfields with a cheaper technology \& lower operating cost.

- Model offers guidance on when to rescale, $\&$ the value of the rescale option coefficient.

- Increasing price volatility has mixed indications for early rescaling or hysteresis.

- Suggest government policies to encourage maximum economic recovery from old oilfields.

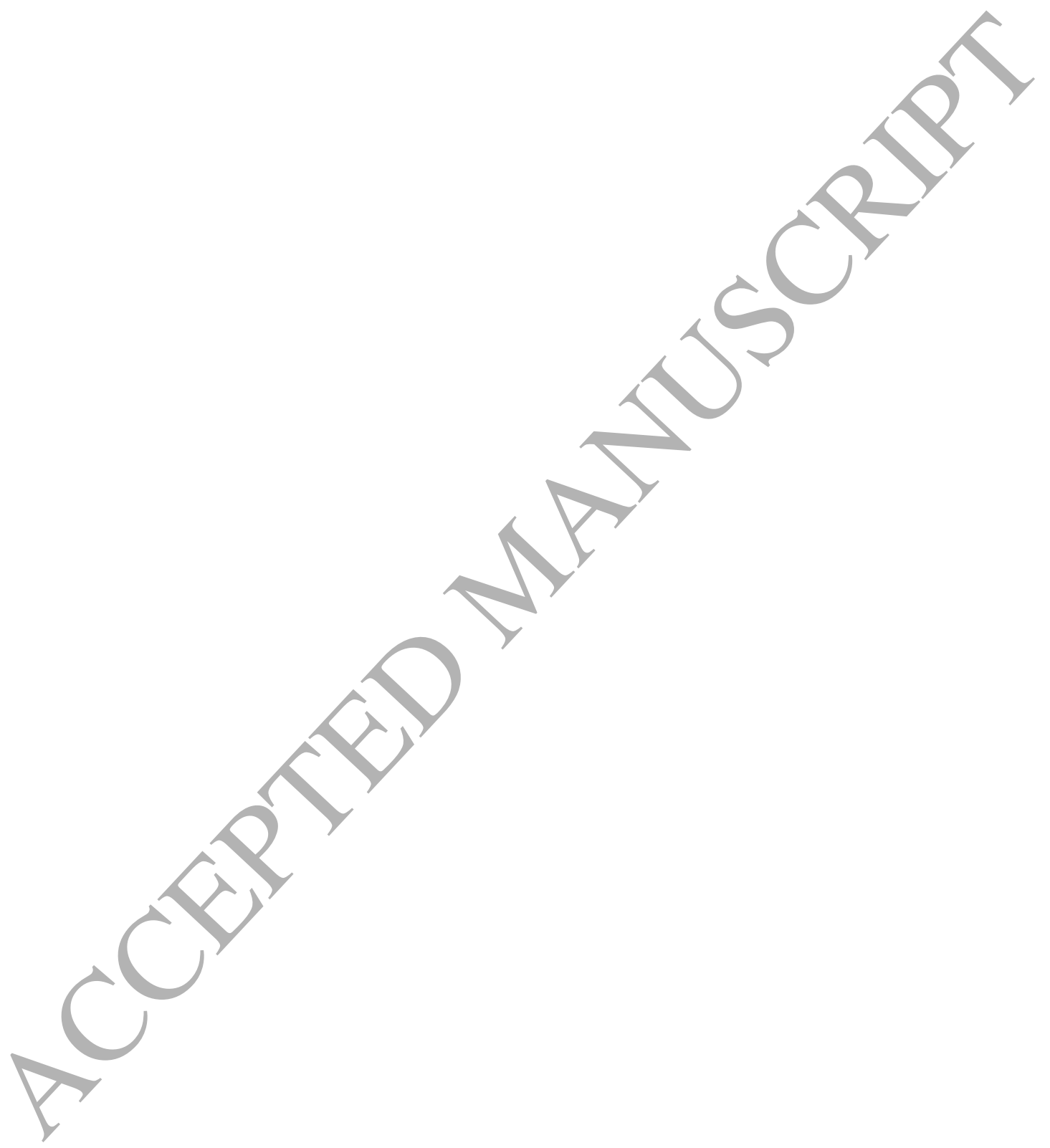




\title{
Rescaling-contraction with a lower cost technology when revenue declines
}

\author{
Roger Adkins ${ }^{\text {a,c }}$ \\ Dean Paxson ${ }^{b}$
}

\section{Third Revision for EJOR 8 February 2019 of EJOR-D-17-01733R2.}

\section{JEL Classifications: D81, G31, H25}

Keywords: OR in natural resources, Technology switching options, Rescaling-contraction, Investment under uncertainty

Acknowledgements: We thank Alcino Azevedo, Kuno Huisman, Artur Rodrigues, the late John Kensinger (the discussant) and other participants in the Real Options Conference, Boston June 2017, and three anonymous referees, for helpful comments on earlier versions of this paper. This research did not receive any specific grant from funding agencies in the public, commercial or not-for-profit sectors.

a Bradford University School of Management, Emm Lane, Bradford BD9 4JL, UK.

r.adkins@bradford.ac.uk

+44 (0)1274233466.

b Alliance Manchester Business School, Booth St West, Manchester, M15 6PB, UK.

dean.paxson@mbs.ac.uk

$+44(0) 1612756456$. Corresponding author

c Honorary Research Fellow, Alliance Manchester Business School, Booth St West, Manchester, M15 6PB, UK.

\section{Abstract}

A mature oil field rescaled contraction describes a switch to a technological alternative more appropriate for the depleted state of an underlying resource. Off-shore oil rigs are an illustration, since the original technological scale designed for very large output flows becomes inappropriate as the operational efficiency declines later in life and facing a dwindling output flow, so a more appropriate extraction technology becomes economic. A real option representation is formulated on a stochastic oil price and deteriorating output volume. We consider investment/divestment decisions both separately, and jointly, which have different implications for government policies and also option values. The resulting model yields analytical (or semi-analytical) results indicating that immediate switching to the lower cost technology could sometimes be hastened as the price volatility increases, depending on the current revenue, if divestment and switching are considered jointly. However, greater volatility could also promote hysteresis. 


\section{Introduction}

We investigate the viability of implementing a rescale policy for mature oilfields (and similar problems) under declining periodic output volumes and volatile oil prices. This is formulated as a real option model, which provides the revenue threshold justifying switching from a conventional to a more appropriate technology and compares the economics of this policy with abandonment, initially in an analytical form.

While a replacement constitutes a like-for-like exchange of a deteriorated productive asset for a brand-new version, a rescaling-contraction is defined here as a switch to a more appropriate technology used specifically in extracting a mature exhaustible resource. The erosion in the economic prospects for a conventional technology due to continuous deterioration in productivity and efficiency, usually associated with cumulative output, is often a prompt for appraising its qualities relative to an appropriate technology operating at a lower output but with a lower operating cost. Off-shore platforms (installations, rigs) are an interesting illustration. Typically, these large-scale extraction facilities, suitable for the largest discoveries, carry commensurately large capital and operating costs. The viability of largescale installations becomes increasingly questionable during their end-of-life stage due to the reduction in the extraction rate and decline in the reserve volume, a business state that becomes increasingly acute as oil prices decline. The inevitable outcome is abandonment, unless a rescaling-contraction to a small-scale, appropriate technology with lower operating costs is economically justified.

Our formulation is an abstracted illustration of the current state of many off-shore United Kingdom continental shelf (UKCS) oil facilities, representing a mature off-shore basin with operating asset ages exceeding 30 years. From its peak in 1999, production has steadily declined until 2014 at an annual rate of about 7\% . The Wood (2014) report focuses on maximizing economic recovery, as $70 \%$ of the UKCS decline is considered to be due to production inefficiencies, compounded by a lack of investment in new technology. This report recommends increased asset stewardship through technological advancements having the potential to increase efficiencies and enhance recovery rates and volumes, while

\footnotetext{
${ }^{1}$ In contrast, 2015-2916 experienced a recovery due to new field openings. Production data on each field are available from http://data-ogauthority.opendata.arcgis.com/pages/production. A primary stated objective of the Oil and Gas Authority is MER UK (maximise economic recovery from the UKCS).
} 
maximizing the economic extension of the field life. Those fields most susceptible to abandonment are classified as marginal, characterized as having low remaining recoverable reserves, low production volume, and unfavourable economics.

Various authors focus on different critical factors in off-shore oil field abandonment decisions. Kemp (1992) considers the current operating and abandonment costs, the role of fiscal relief and security concerns, along with fluctuating oil prices, field interdependency and technological progress. A net present value analysis shows a greater incentive to postpone abandonment in the presence of a less steep production decline rate, higher abandonment costs and a higher discount rate. The externalities associated with decommissioning off-shore installations for all maritime users, including environmental groups and governments as well as the oil companies, are studied by Osmundsen and Tveterås (2003). Disposal costs can vary by field even for the same geographic region, while differences in disposal strategies can lead to varying reputational and cost consequences apportioned amongst the players. Parente et al. (2006) consider the role of a periodic ex-ante tax deductibility of the decommissioning cost despite constituting an ex-post expense and the question of assigning decommissioning responsibility for an installation following a transfer of rights during the project life.

One of the earliest real option analysis of entry and exit thresholds in natural resources is Tourinho (1979), who advocates the inclusion of a holding cost to ensure exercise, see also Adkins and Paxson (2013). Paddock et al. (1988) show that oil field lease values increase with greater volatility. The models of Bjerksund and Ekern (1990) for oil development value include the analytical American perpetuity real call option. Laughton (1998) shows that both oil price and reserve volume uncertainties enhance the prospect value but distinctively influence the exercise of the various decisions. McCormack and Sick (2001) discuss the use of real options in valuing undeveloped reserves. Dias (2004) advocates that a real options format is appropriate for evaluating oil extraction decisions due to the inherent revenue uncertainty and managerial flexibility. Chorn and Shokhor (2006) apply a jump diffusion model for evaluating the emergence of new information in petroleum developments. Muehlenbachs (2009) considers innovations in costs of reactivation of idle oil wells. Guedes and Santos (2016) assess the value of an offshore oil development installation involving a sequence of interdependent decisions modelled as options and show a high value associated with abandonment. The role of $\mathrm{CO}_{2}$ in enhancing oil recovery rates as well as mitigating its 
potentially harmful effects on the environment is assessed by Compernolle et al. (2017), who consider two stochastic factors.

A technology rescale with its more favourable properties can be conceived as a discrete sequential investment style model for an active productive asset that can assume more than one state. The earliest formulations of this type are the continual switching models between an active and suspended state as presented by Brennan and Schwartz (1985) and Dixit (1989). Trigeorgis (1996) provides a basic model of the option to contract, where the investor has the opportunity to choose once in one year's time whether to make the full remaining investment expenditure to obtain the full project value, or alternatively a reduced expenditure (equal to the cost savings) for a proportion of the project value. This is equivalent to a European put option, so there is no flexibility of investment timing, or a project value that would justify immediate investment (option value is shown as a function of project value). Although the basic approach is shown as a binomial discrete time model, alternative computational methods are suggested for an American put, which could reflect sensitivity to changes in expected interest rates, drifts and future volatility. In an extension to multiple states, Paxson (2005) develops a contraction-expansion model having contraction as one of its states, characterized by a more favourable operating cost structure (for lower quality and lower scale) in the presence of a profit decline. These early models typically are based on a single stochastic factor and ignore technological innovations. Insley (2017) examines the effect of carbon tax schemes on the optimal timing of construction, production and abandonment of oil sands extraction.

In contrast, Malchow-Møller and Thorsen (2005) propose a repeated investment model of potentially ever-improving technological advances, which is installed whenever a sufficient productivity deterioration is suffered. Siddiqui and Maribu (2009) formulate a one-factor investment model for the electricity generation industry to examine the economic justification for a distribution upgrade and show the significance of volatility on the policy decision. Siddiqui and Fleten (2010) develop a process representation to model a real option formulation of a switch to an alternative energy technology having a more favourable cost structure. Kort et al. (2010) show that despite the intrinsic flexibility of a stepwise versus a lumpy investment strategy, greater uncertainty makes the latter more attractive. However, the former is always superior if a choice exists on the installed capacity level, Chronopoulos et al. (2016). Chronopoulos and Siddiqui (2015) assess the merits of alternative strategies 
through an optimal timing model for innovative technology replacement in the presence of price and technological arrival uncertainty. In an extension, Chronopoulos and Lumbreras (2017) assess the effect of risk aversion on the reluctance to switch between regimes under market and technological uncertainty to show that changes in volatility, risk aversion and innovation significantly affect the optimal policy decision.

Mutually exclusive investments are examined by Dixit (1993), while Décamps et al. (2006) point out that the Dixit solution is not necessarily correct in all contexts, as discussed below. Other authors consider several factors, sometimes two stochastic factors. Bobtcheff and Villeneuve (2010) extend the Décamps et al. (2006) approach to stochastic input and output prices. Adkins and Paxson (2011a), Dockendorf and Paxson (2013) and Støre et al. (2018) examine two-stochastic-factor models on making a viable irreversible/switch between two different inputs (outputs) to show that both sources of uncertainty are crucial in the optimal decision.

Several authors have addressed Décamps type problems. Fleten et al. (2007) is an early application of the Décamps method to a choice between mutually exclusive projects of different scale, simplified as the solution to four equations with four unknowns. Fleten et al. (2011) considers basic mutually exclusive investments of lower and higher scale, and also a lower scale with a switching option to upgrade to the higher scale. Hagspiel et al. (2016) examine a generation investment problem, deciding when to replace a declining product. Lavrutich (2017) mentions that the Décamps problem is similar to hers insofar as "the optimal investment intervals of two projects do not intersect, creating the inaction region". Lukas et al. (2017) note a hysteresis while considering choice among three mutually exhaustive investments, providing a numerical solution. Dumortier et al. (2017) cite Décamps, and provide a numerical solution for mean reversion and two-way switching. Guerra et al. (2018) mention Décamps in the conclusion, as a possible extension, to their simultaneous solution of ten equations. Truong et al. (2018) examine a problem close to ours, studying several alternative climate change abatement technologies, when there is uncertainty, but with a quite different application. Optimal investment for a single project is compared to sequential investments and alternative investments, citing Décamps.

Our aim is to develop and analyse a discrete sequential investment problem characterizing the rescale trade-off between continuing to use the conventional incumbent technology for oil 
extraction versus installing an appropriate technology with lower operating costs, under price uncertainty and a declining periodic output volume. Our real option formulation employs a perpetuity to value the residual reserve volume. However, a divestment option is introduced to ensure a finite time termination as advocated by Preinreich (1940) for analytical appraisal models based on an infinite lifetime assumption. The divestment option incurs a significant decommissioning cost on exercise and provides the means for terminating the implied infinitely lived asset.

There are four principal contributions made by this paper. First, we develop a one stochastic and one deterministic factor representation in which the output price follows an assumed stochastic process and the output volume declines deterministically with cumulative production, but despite this complexity there is initially an analytical solution. Second, we are concerned with determining the revenue thresholds that discriminate between justifying a conventional technology divestment without rescaling, and appropriate technology rescaling but with the conventional technology divested, under separate and then joint formulations. A rescaling-contraction is economically justified when the decline in the value of the periodic extracted oil output and investment cost is offset by the value of the reduced operating costs. Thirdly, we provide some insights on rescaling with partial divesting. Finally, numerical analysis is used to show the sensitivity of the threshold justifying extending the life of mature fields to changing several government policy variables.

Questions that we address are: (1) how does the volatility of oil prices (the stochastic element) affect the timing (thresholds) of divestment, and/or adoption of lower cost technology? (2) What is the difference between divestment and/or switching timing with and without a new lower cost technology, under the Dixit and adapted Décamps methods? (3) Would government subsidies, tax credits or other allowances which amount to partial divestment affect the timing of disinvestment and/or rescaling-contraction? (4) What other feasible government policies could motivate extending the life of mature fields?

Generally, we find that by treating the divestment and switching investment decisions as a separate formulation, both the exercise thresholds and option coefficients decrease as volatility increases, but at different rates. A different pattern emerges when the divestment and investment switching decisions are treated in a joint formulation. As the volatility 
increases, the divestment threshold decreases but the switching threshold increases, so the inaction region widens.

Several simplifying assumptions are introduced to make the real-option switching model analytically tractable. Switching once only between the two technologies, or between the incumbent technology and divestment, is treated as irreversible and instantaneous. Switching and any periodic operating costs are assumed to be known and constant. Although holding costs, royalties, tax, tax depreciation allowances and government subsidies (which could alter the effective investment, operating and decommissioning costs) are not directly considered in the analysis, it is straightforward to include them with an additional level of complexity, Adkins and Paxson (2017).

The paper is organized as follows. The real option model derivations are developed in section 2. Section 3 explores numerical sensitivity analysis to gain further insights into the model solution. The paper ends with conclusions mostly about plausible government policies for extending the life of mature fields, and model limitations and extensions.

\section{Optimal Selection}

We seek to optimize the value an owner can capture from a mature nearly-depleted oil reserve. Up until now, a single large-scale technology solution has been deployed to extract the oil from the reserve. But the owner is facing the challenge of closing down production because the net revenue flow is becoming uneconomic. The available alternatives are between policy (a) of divesting the associated assets and terminating oil extraction, and policy (b) of diyesting the associated assets but switching to a small-scale extraction technology, which is designed to be more appropriate for the current underlying conditions of low oil prices, low output flows, or both. We suppose there are just two oil extraction technologies, labelled the large-scale incumbent $X$ normally applied at inception and the small-scale appropriate ${ }^{2} Y$. Typically, very large oil discoveries are served just by $X$, and its scale is reflected in the magnitude of the various costs incurred. Commissioning a rig based

\footnotetext{
${ }^{2}$ The binary representation of technology as being conventional and appropriate is an abstraction, since in reality, offshore oil platforms vary in size with fixed platforms being the largest and floating production storage offloading facilities, possibly unattended and remotely controlled, being the smallest. The economics are commensurate with their size. Specialist firms, such as Atkins Oil and Gas, Aquaterra Energy, Genesis Oil and Gas Consultants, and MFDevCo, offer switching advice on effective facilities conducive to mature field economics. There are several companies specializing in appropriate investments for mature fields such as EnQuest PLC. "Enhanced oil recovery" methods for mature fields may not require new installations, but perhaps have some of the same problems as discussed herein, including technological innovations.
} 
on $X$ requires not only substantial capital expenditures but also significant periodic operating expenses, which have to be offset by both high output flows and high oil prices. As the residual oil reserve declines with extraction, eventually the gross revenue will not cover the operating expense. If technology $X$ becomes uneconomic, the owner has to choose between policy (a) and (b). The small-scale appropriate technology $Y$ is specially designed for low volume production for mature fields because of its lower operating expense. The economic replacement of $X$ by $Y$ demands that the resulting gain in reduced operating expense is sufficient to compensate any revenue fall as well as the switching investment cost. Our intent is to identify the optimal conditions favouring the adoption of either policy (a) or (b) in the context of a stochastic oil price and a deterministically declining extraction flow.

The problem of selecting between two or more alternative opportunities with different payoffs under uncertainty is similar to that studied by Dixit (1993) and Décamps et al. (2006), except for the output decline shifts. According to Dixit (1993), for a sufficiently high initial revenue generated by $X$, the optimal choice is switching to the alternative having the higher option value, either (a) or (b), as soon as its respective threshold is attained. However, if the threshold exceeds initial revenue, then the alternative having the higher net present value is selected with immediate effect. Décamps et al. (2006) contest the validity of the second part of this rule. They demonstrate that at the point of indifference where the net present values for the two alternatives are equal, it is not optimal to invest in either, since there exists an inaction region where the best policy is to wait until additional information clearly discriminates in favour of one of the alternatives. The optimal policy prescriptions for Dixit (1993) and Decamps et al. (2006) are illustrated in Figure 1. This is adapted for a declining revenue stream, assuming that there are two policy alternatives (a) and (b), and policy (b) commands a greater switch option value. If the initial revenue under $X$ denoted by $v_{X}$ exceeds the policy (b) switch threshold $\hat{v}_{S X}$, then the optimal policy for either prescription is to wait for additional information until the revenue declines sufficiently to $v_{X}=\hat{v}_{S X}$, when (b) is exercised. For an initial revenue $v_{X}<\hat{v}_{S X}$, the Dixit (1993) prescription is to invest in whichever policy alternative possesses the greater net present value. In contrast, the Décamps et al. (2006) prescription is to invest in policy (b) if the initial revenue exceeds or equals the jointly obtained upper threshold denoted by $\hat{v}_{S S X}$ so requiring $v_{X} \geq \hat{v}_{S S X}$, but in policy (a) if $v_{X}$ lies at or below the jointly obtained lower threshold denoted by $\hat{v}_{D D X}$ so 
$v_{X} \leq \hat{v}_{D D X}$. The lower and upper thresholds $\left(\hat{v}_{D D X}, \hat{v}_{S S X}\right)$ specify an inaction region where the best policy is to wait for additional information that distinctly justifies exercising one of the two policies (see Appendix A and B).

Figure 1: Policy Prescriptions

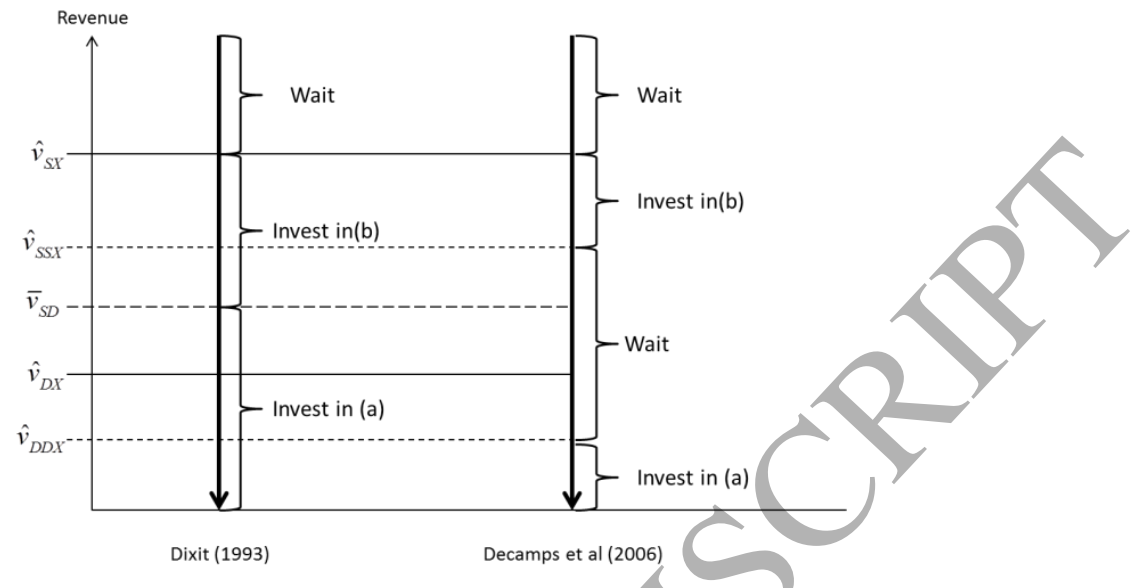

This figure represents the optimal policy prescriptions of Dixit (1993) and Décamps et al. (2006) for an installation facing uncertain but inevitably declining revenues, denoted by $v$. It is assumed that policy (b) has the greater option value. We use the notation defined in Table 1 . The separately obtained thresholds for policy (b) and policy (a) are $\hat{v}_{S X}$ and $\hat{v}_{D X}$, respectively. For an initial revenue $v<\hat{v}_{S X}$, the inaction region defined by Décamps et al. (2006) is specified by the upper and lower thresholds, $\hat{v}_{S S X}$ and $\hat{v}_{D D X}$, respectively. The stopping region for policy (b) is given by $\left(\hat{v}_{S S X}, \hat{v}_{S X}\right)$ and for (a) by $\left(0, \hat{v}_{D D X}\right)$. The indifference point defined for equal net present values is denoted by $\bar{v}_{S D}$. Adapting Décamps et al. (2006), we expect $\hat{v}_{S X}>\hat{v}_{S X X}>\hat{v}_{D X}>\hat{v}_{D D X}$.

\subsection{The Stochastic Model}

The model is formulated on the generic stochastic variable $v$, which denotes the periodic revenue rendered by the oil installation. Where necessary, we append the subscript $X$ or $Y$ to indicate the underlying technology. Revenue is defined as the product of a stochastic oil price $p$ and a deterministically declining periodic output flow $q$, so $v=p q$. The oil price is described by a geometric Brownian motion process, see Pindyck (1999):

$$
\mathrm{d} p=\alpha_{p} p \mathrm{~d} t+\sigma p \mathrm{~d} W
$$

where $\alpha_{p}$ denotes the known drift rate, $\sigma$ the price volatility, and $\mathrm{d} W$ an increment of the standard Wiener process. The output flow follows the declining balance form:

$$
\mathrm{dq}=-\theta q \mathrm{~d} t
$$

where $\theta>0$ denotes a known constant depletion rate. The residual reserve volume is $q_{R}=q / \theta$, so for any given $q_{R}$ a flow increase (decrease) has to be compensated by a commensurate increase (decrease) in the depletion rate. Using Ito's Lemma, Brennan and 
Schwartz (1985), the evolution of the value of an active incumbent firm with options to make (further) investments or divest, in a risk-neutral context, with periodic operating expense $f$, should satisfy the following differential equation:

$$
\frac{1}{2} \sigma^{2} p^{2} \frac{\partial^{2} F}{\partial p^{2}}+(r-\delta) p \frac{\partial F}{\partial p}-\theta q \frac{\partial F}{\partial q}+p q-f-r F=0
$$

where $F$ denotes the option value, $\delta=r-\alpha_{p}>0$ the oil convenience yield and $r$ is the riskfree rate. Based on the American perpetuity solution, the valuation function $V$ satisfying (3), Adkins and Paxson (2011b), takes the form:

$$
V=F+\frac{p q}{\delta+\theta}-\frac{f}{r}=A_{1} p^{\beta_{1}} q^{\gamma_{1}}+A_{2} p^{\beta_{2}} q^{\gamma_{2}}+\frac{p q}{\delta+\theta}-\frac{f}{r}
$$

where $A_{1}, A_{2}$ are two non-negative coefficients, and the generic parameters $\beta$ and $\gamma$ are related through the characteristic equation:

$$
Q(\beta, \gamma)=\frac{1}{2} \sigma^{2} \beta(\beta-1)+(r-\delta) \beta-\theta \gamma-r=0 .
$$

The principle of similarity can be shown to apply to all model versions. This is because the elasticities of the net gain due to a switch arising from an oil price change or from an identical oil volume change are equal, irrespective of whether the switch is to policy (a) or (b). This can be verified by examining the respective smooth-pasting conditions. It implies that $\gamma_{1}=\beta_{1}, \gamma_{2}=\beta_{2}$, Paxson and Pinto (2005), and consequently:

$$
\beta_{1}, \beta_{2}=\left(\frac{1}{2}-\frac{r-\delta-\theta}{\sigma^{2}}\right) \pm \sqrt{\left(\frac{1}{2}-\frac{r-\delta-\theta}{\sigma^{2}}\right)^{2}+\frac{2 r}{\sigma^{2}}}
$$

where $\beta_{1}>1$ and $\beta_{2}<0$. Both $\beta_{1}, \beta_{2}$ vary with the depletion rate $\theta$, so for $\theta_{i}, i=X, Y$ the power parameters are expressed as $\beta_{i 1}, \beta_{i 2}$. If $\theta_{X}>\theta_{Y}$, then $\beta_{X 1}>\beta_{Y 1}, \beta_{X 2}>\beta_{Y 2}$. Further, because of similarity, the analysis can be framed in terms of a single variable $v$ instead of the two variables, $p$ and $q$, so (4) becomes:

$$
V=A_{1} v^{\beta_{1}}+A_{2} v^{\beta_{2}}+\frac{v}{\delta+\theta}-\frac{f}{r} .
$$

The potential choices facing an owner actively deploying technology $X$ to extract oil from a mature reservoir are illustrated in Figure 2. This shows that regardless of the technology deployed, the active process of oil extraction is eventually brought to an end and terminated when the installation is optimally divested. This effectively limits the infinite lifetime implied by the American perpetuity solution to a finite if uncertain duration. The consequence of declining oil revenues is to motivate the owner to evaluate the comparative merits of the 
policy (a) of divesting the installation based on $X$, and (b) of switching to $Y$ after divesting $X$. Both opportunities are treated as if the commissioning can be effected instantaneously. For (b), it is initially assumed that technology $X$ is entirely divested, but this requirement is subsequently relaxed. The possibility of temporary suspension as analysed by Mossin (1968), Brennan and Schwartz (1985) and Dixit (1988) is excluded because of the substantial costs in maintaining the oil installation assets inactive but ready for reactivation, which may be feasible for on shore idle wells, see Muehlenbachs (2009). Although policies (a) and (b) are inter-dependent and thereby require a joint analysis, we commence by evaluating each policy separately, and then jointly. A listing of the variables used in the analysis is presented in Table 1.

$\begin{array}{ll}p & \text { Oil price } \\ q & \text { Periodic output flow } \\ v=p q & \text { Periodic output value (revenue) } \\ f & \text { Periodic operating cost } \\ D & \text { Divestment value (decommissioning cost) } \\ K_{Y} & \text { Switch investment cost } \\ \hat{v}_{D X} & \text { Optimal divestment threshold for technology } \mathrm{X} \\ \hat{v}_{D Y} & \text { Optimal divestment threshold for technology } \mathrm{Y} \\ \hat{v}_{S X} & \text { Optimal switch threshold for technology } \mathrm{Y} \\ \hat{v}_{D D X} & \text { Jointly obtained } X \text { divestment threshold } \\ \hat{v}_{S S X} & \text { Jointly obtained switch threshold } \\ A_{2 D X} & \text { Option coefficient for divesting technology } X \\ A_{2 D Y} & \text { Option coefficient for divesting technology } \mathrm{Y} \\ A_{2 X} & \text { Jointly obtained switch option coefficient to switch } \\ A_{1 X} & \text { Jointly obtained } X \text { divestment option coefficient }\end{array}$

In our notation, lower-case variables represent continuous quantities, such as the periodic output flow and operating cost, while upper-case variables are one-off quantities, such as the switch cost and divestment value. Optimal thresholds are

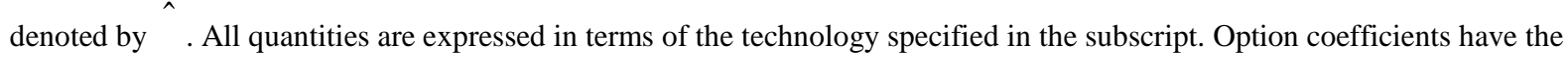
subscript 1 or 2 , denoting investment-style or divestment-style (switch) opportunities, respectively. 
Figure 2: Potential Choices

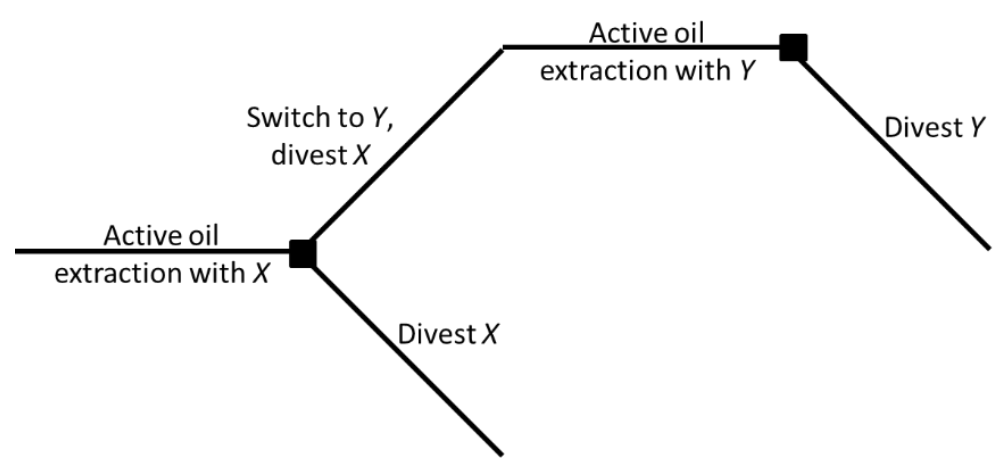

\subsection{Separate Formulation}

We first evaluate the divestment opportunity that is available to an owner actively extracting oil using technology $X$ assuming that policy (b) is not available. In (7), the divestment option value is redefined as $A_{2 D X} \hat{v}_{D X}^{\beta_{X 2}}$ where $A_{2}=A_{2 D X} \geq 0$ denotes the option coefficient and $v=v_{D X}$ the revenue for the active installation while $A_{1}=0$, since the option value increases with declining revenues. Divesting entails foregoing the net revenue value $\hat{v}_{D X} /\left(\delta+\theta_{X}\right)-f_{X} / r$ and the divestment option, but receiving (paying) the divestment value $D_{X}$ in compensation. The value-matching relationship expressed in terms of the revenue threshold $\hat{v}_{D X}$ is given by:

$$
\frac{\hat{v}_{D X}}{\delta+\theta_{X}}-\frac{f_{X}}{r}+A_{2 D X} \hat{v}_{D X}^{\beta_{X 2}}=D_{X}
$$

(8) combined with its associated smooth-pasting condition

reveals that:

$$
\frac{1}{\delta+\theta_{X}}+\beta_{X 2} A_{2 D X} \hat{v}_{D X}^{\beta_{X 2}-1}=0
$$

$$
\begin{gathered}
\hat{v}_{D X}=\frac{-\beta_{X 2}}{1-\beta_{X 2}}\left(D_{X}+\frac{f_{X}}{r}\right)\left(\delta+\theta_{X}\right) \\
A_{2 D X}=\frac{\hat{v}_{D X}^{1-\beta_{X 2}}}{-\beta_{X 2}\left(\delta+\theta_{X}\right)}=\left(\frac{D_{X}+f_{X} / r}{1-\beta_{X 2}}\right)^{1-\beta_{X 2}}\left(-\beta_{X 2}\left(\delta+\theta_{X}\right)\right)^{-\beta_{X 2}} .
\end{gathered}
$$

When policy (a) is treated separately, the optimal decision is to divest whenever $v \leq \hat{v}_{D X}$ since divestment is motivated by low revenues. The option value for divesting $X$ is characterized by $A_{2 D X} \geq 0$, which is an increasing function of $D_{X}, f_{X}, \theta_{X}, \delta$. A negative 
abandonment value, or a positive decommissioning charge, is permissible only if $f_{X} / r>-D_{X}$, and the option to divest loses its attractiveness as the decommissioning charge increases since $\beta_{X 2}<0$. There is an expression similar to (10) for the option coefficient when divesting $Y$, with the subscript $X$ being replaced by $Y$.

Policy (b), the alternative to (a), involves committing a capital expenditure $K_{Y}$ to rescale to $Y$ with its lower depletion rate $\theta_{Y}$ after divesting $X$. Assuming (a) is unavailable, then switching to policy (b) entails foregoing the net revenue value under $X, v_{X} /\left(\delta+\theta_{X}\right)-f_{X} / r$, and incurring a net capital expenditure, $K_{Y}-D_{X}$. The resulting net revenue value rendered by $Y$ is $v_{Y} /\left(\delta+\theta_{Y}\right)-f_{Y} / r$, where $v_{Y}$ and $f_{Y}$ denote the revenue and operating expense under $Y$. Since the residual oil reserve volume is equal under either technology, their respective output flows, $q_{X}, q_{Y}$ are related through $q_{X} / \theta_{X}=q_{Y} / \theta_{Y}$. Assuming an instantaneous switch with the same oil price, $v_{X} / \theta_{X}=v_{Y} / \theta_{Y}$. We expect that at the smaller scale, $Y$ has a lower output flow so $q_{Y}<q_{X}$ and $\theta_{Y}<\theta_{X}$. Since the gain in net revenue value rendered by the switch has to more than compensate the net switching cost $K_{Y}-D_{X}$, which is positive in the context of a positive decommissioning charge, then:

$$
\frac{f_{X}-f_{Y}}{r}+v_{Y}\left(\frac{1}{\delta+\theta_{Y}}-\frac{\theta_{X}}{\theta_{Y}\left(\delta+\theta_{X}\right)}\right)
$$

has to be positive, which implies $f_{X}>f_{Y}$ because:

$$
\frac{1}{\delta+\theta_{Y}}-\frac{\theta_{X}}{\theta_{Y}\left(\delta+\theta_{X}\right)}=-\frac{\delta\left(\theta_{X}-\theta_{Y}\right)}{\theta_{Y}\left(\delta+\theta_{X}\right)\left(\delta+\theta_{Y}\right)}<0
$$

An irreversible switch from $X$ to $Y$ is only economically justified provided that any ensuing gross revenue loss plus the switching capital expenditure are more than compensated by gains achieved from the resulting lower periodic operating costs.

Similar to (a), switching to policy (b) and adopting $Y$ is motivated by low revenues. We denote the optimal policy (b) switching threshold by $\hat{v}_{S X}$ such that continued extraction under $X$ is maintained while $v_{X}>\hat{v}_{S X}$, but $Y$ replaces $X$ whenever $v_{X} \leq \hat{v}_{S X}$. This implies that the switch option function for (b) takes the identical form as that for the divest option with (a). Although measured in terms of revenue under $X$, the rule is also expressible in terms of 
revenue under $Y, \hat{v}_{S Y}$, through the relationship $\hat{v}_{S Y}=\theta_{Y} \hat{v}_{S X} / \theta_{X}$, but the former is preferred to make policies (a) and (b) directly comparable. An economically justified switch requires that the rendered incremental net gains at least compensate the incremental net opportunity costs, where both gains and costs are interpreted to include any embedded options. Specifically, gains due to the operating expense change and the embedded $Y$ divestment option have to at least exceed losses arising from the revenue fall, the net switching cost as well as the foregone switching option value. The value matching relationship is:

$$
\frac{\hat{v}_{S X}}{\delta+\theta_{X}}-\frac{f_{X}}{r}+A_{2 S X} \hat{v}_{S X}^{\beta_{X 2}}=\frac{\hat{v}_{S X} \theta_{Y}}{\theta_{X}\left(\delta+\theta_{Y}\right)}-\frac{f_{Y}}{r}-\left(K_{Y}-D_{X}\right)+A_{2 D Y} \frac{\theta_{Y}^{\beta_{Y 2}}}{\theta_{X}^{\beta_{X 2}}} \hat{v}_{S X}^{\beta_{Y 2}},
$$

where $A_{2 S X}, A_{2 D Y}$ denote the option coefficient for a switch and $Y$ divestment, respectively. $A_{2 D Y}$ is obtained in the same way as for $X,(10)$ :

$$
A_{2 D Y}=\left(\frac{D_{Y}+f_{Y} / r}{1-\beta_{Y 2}}\right)^{1-\beta_{Y 2}}\left(-\beta_{Y 2}\left(\delta+\theta_{Y}\right)\right)^{-\beta_{Y 2}} \text {. }
$$

The smooth-pasting condition for (12) can be expressed as:

$$
\frac{\hat{v}_{S X}}{\delta+\theta_{X}}+\beta_{X 2} A_{2 S X} \hat{v}_{S X}^{\beta_{X 2}}=\frac{\hat{v}_{S X} \theta_{Y}}{\theta_{X}\left(\delta+\theta_{Y}\right)}+\beta_{Y 2} A_{2 D Y} \frac{\theta_{Y}^{\beta_{Y 2}}}{\theta_{X}^{\beta_{Y 2}}} \hat{v}_{S X}^{\beta_{Y 2}},
$$

which when combined with (12) yields:

$$
\begin{aligned}
\left.\hat{v}_{S X} \frac{\delta\left(\theta_{X}-\theta_{Y}\right)}{\theta_{X}\left(\delta+\theta_{X}\right)\left(\delta+\theta_{Y}\right)}\right) \\
\quad=\frac{-\beta_{X 2}}{1-\beta_{X 2}}\left(\frac{f_{X}}{r}-\frac{f_{Y}}{r}+D_{X}-K_{Y}\right)+\frac{\beta_{Y 2}-\beta_{X 2}}{1-\beta_{X 2}} A_{2 D Y} \frac{\theta_{Y}^{\beta_{Y 2}}}{\theta_{X}^{\beta_{Y 2}}} \hat{v}_{S X}^{\beta_{Y 2}} .
\end{aligned}
$$

There is apparently no closed-form solution for $\hat{v}_{S X}$, (15) if $A_{2 D Y}>0$. However, some insights into the properties of $\hat{v}_{S X}$ are obtainable by assuming the $Y$ divestment optionality is absent. We set $\hat{v}_{S X 0}=\hat{v}_{S X}$ to distinguish this case. Since $0<\beta_{X 2} /\left(\beta_{X 2}-1\right)<1$, a viable switch requires the revenue value change to be less than the change in overall costs when $A_{2 D Y}=0^{3}$. Also, $\hat{v}_{S X 0}$ is feasible only if the gain from foregoing $f_{X}$ exceeds the return on net capital expenditure $r\left(K_{Y}-D_{X}\right)$ and $f_{Y}$. Since $\hat{v}_{S X 0}$ is linearly dependent on $K_{Y}, f_{Y}, D_{X}, f_{X}$, a less unfavourable $Y$ cost structure (increases in $K_{Y}, f_{Y}$ ) but a more favourable $X$ cost structure

\footnotetext{
${ }^{3}$ This is a simplifying case eliminating the second part of the RHS of (15), but it requires an imagination that there could be no option to divest ever after the switch.
} 
(decreases in $f_{X}, D_{X}$ ) each produces a decrease in $\hat{v}_{S X 0}$ thereby forcing the switch decision to be deferred, so if $D_{X}<0$, a decommissioning charge increase produces a deferral.

The consequence of $Y$ divestment optionality being present rather than absent, $A_{2 D Y}>0$, is to defer the optimal switch decision and to raise the switch option value. In (15), since $\beta_{X 2}, \beta_{Y 2}<0$ and $\beta_{X 2}>\beta_{Y 2}$, the inclusion of $Y$ divestment optionality has the effect of reducing the right-hand side value, which causes the threshold solution to fall relative to that in its absence. The magnitude of this effect is reduced for increases in either the threshold value or decommissioning charge. The switch option coefficient $A_{2 S X}$ obtained from (14) is:

$$
A_{2 S X}=\frac{-\delta\left(\theta_{X}-\theta_{Y}\right)}{\beta_{X 2} \theta_{X}\left(\delta+\theta_{Y}\right)\left(\delta+\theta_{X}\right)} \frac{\hat{v}_{S X}}{\hat{v}_{S X}^{\beta_{X 2}}}+\frac{\beta_{Y 2}}{\beta_{X 2}} A_{2 D Y} \frac{\theta_{Y}^{\beta_{Y 2}}}{\theta_{X}^{\beta_{Y 2}}} \frac{\hat{v}_{S X}^{\beta_{Y 2}}}{\hat{v}_{S X}^{\beta_{X}}} .
$$

If $Y$ divestment optionality is absent, $A_{2 D Y}=0$, then $A_{2 S X}=A_{2 S X 0}>0$ since $\beta_{X 2}<0$. In its presence, the effect is to uplift the switch option coefficient since $\beta_{X 2}, \beta_{Y 2}<0$ and to make the switch option more attractive, but its attractiveness recedes as its decommissioning charge increases.

Provided the initial revenue exceeds the thresholds, the choice between policy (a) and (b) is decided by the magnitudes of their option values. This is equivalent to selecting the policy having the greater option coefficient since there is only a single source of uncertainty. No analytical result exists for the ratio of the option coefficients unless we assume the $Y$ divestment optionality to be absent. If we set $A_{2 D Y}=0$, then from (10) and (16):

$$
\frac{A_{2 S X 0}}{A_{2 D X}}=\left[\frac{\delta\left(\theta_{X}-\theta_{Y}\right)}{\theta_{X}\left(\delta+\theta_{Y}\right)}\right]^{\beta_{X 2}}\left[1-\frac{K_{Y}+f_{Y} / r}{D_{X}+f_{X} / r}\right]^{1-\beta_{X 2}} .
$$

For policy (b)/to be preferred, $A_{2 S X 0}>A_{2 D X}$, both $\theta_{X}-\theta_{Y}>0$ and $\left(K_{Y}+f_{Y} / r\right) /\left(D_{X}+f_{X} / r\right)$ need to be as small as possible. This suggests that a smaller scale technology is optimal and selected to replace the incumbent provided its depletion rate is close to that for $X$ and the overall expenditures for operating $Y$ are low. If a switch is judged to be optimal in the absence of $Y$ divestment optionality, then it is also optimal in its presence due to (16). 


\subsection{Joint Formulation}

Décamps et al. (2006) demonstrate that the joint evaluation of mutually-exclusive policies results in an inaction region. To start, we presume the separately evaluated preferred policy to be (b) so $A_{2 S X}>A_{2 D X}$ and $\hat{v}_{S X}>\hat{v}_{D X}$. If $v_{X}<\hat{v}_{S X}$, the owner is favoured with two options. The first relates to policy (a), which is represented by a decreasing function of revenue because lower revenues motivate its exercise, while the second relates to policy (b), which is represented an increasing function of revenue because higher revenues motivates its exercise. A significant downward movement in revenue may be sufficient to trigger policy (a) because the consequential first option increase over-compensates the second option decrease. Similarly, policy (b) may be triggered by a significant upward movement in revenue because the consequential second option increase over-compensates the first option decrease. This results in the inaction region, which can be specified by $\left(\hat{v}_{D D X}, \hat{v}_{S S X}\right) \subset\left(0, \hat{v}_{S X}\right)$, where $\hat{v}_{D D X}<\hat{v}_{S S X}$ denote lower and upper thresholds, respectively. If $v_{X} \leq \hat{v}_{D D X}$ then the optimal policy is (a), if $v_{X} \geq \hat{v}_{S S X}$ then the optimal policy is (b), while if $v_{X} \in\left(\hat{v}_{D D X}, \hat{v}_{S S X}\right)$ then the optimal policy is to maintain continued extraction under $X$.

We now extend the Décamps et al. (2006) correction to the divestment-switch model. The lower and upper thresholds are obtained from two respective value-matching relationships, the first representing the optimal conditions prevailing when policy (a) is exercised, and the second when (b) is exercised. The relationships are drawn from (8) and (12), respectively:

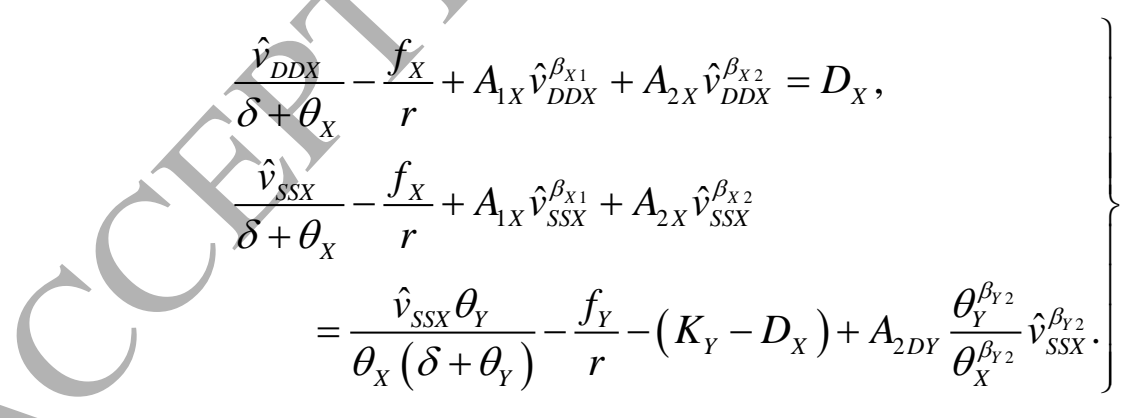

The option values, $A_{1 X} v_{X}^{\beta_{X 1}}, A_{2 X} v_{X}^{\beta_{X 2}}$ for $v_{X}<\hat{v}_{S X}$, representing respectively the opportunity values of policy (a) and (b), are decreasing and increasing functions of $v_{X}$. Despite both policies involving divestment, the opportunity value for policy (b) is an increasing function since for $v_{X} \in\left(\hat{v}_{D D X}, \hat{v}_{S S X}\right)$ a positive $v_{X}$ change signals its likely exercise. The option coefficients, $A_{1 X}, A_{2 X}$ are treated as non-negative because the options are value-creating. 
Note that $A_{1 X}$ are naturally not in (8) or (12). In line with Décamps et al. (2006), we expect $\hat{v}_{D D X}<\hat{v}_{D X}<\hat{v}_{S S X}<\hat{v}_{S X}$. From (18) the values for the two option coefficients are:

$$
\left[\begin{array}{l}
A_{1 X} \\
A_{2 X}
\end{array}\right]=\left[\begin{array}{l}
\mathrm{d}^{-1}\left(c_{2} \hat{v}_{D D X}^{\beta_{X 2}}-c_{1} \hat{v}_{S S X}^{\beta_{X 2}}\right) \\
\mathrm{d}^{-1}\left(-c_{2} \hat{v}_{D D X}^{\beta_{X 1}}+c_{1} \hat{v}_{S S X}^{\beta_{X 1}}\right)
\end{array}\right],
$$

where:

$$
\begin{aligned}
\mathrm{d} & =\hat{v}_{D D X}^{\beta_{X 2}} \hat{v}_{S S X}^{\beta_{X 1}}-\hat{v}_{D D X}^{\beta_{X 1}} \hat{v}_{S S X}^{\beta_{X 2}}, \\
c_{1} & =D_{X}+\frac{f_{X}}{r}-\frac{\hat{v}_{D D X}}{\delta+\theta_{X}}, \\
c_{2} & =\left(\frac{\hat{v}_{S S X} \theta_{Y}}{\theta_{X}\left(\delta+\theta_{Y}\right)}-\frac{f_{Y}}{r}\right)-\left(\frac{\hat{v}_{S S X}}{\delta+\theta_{X}}-\frac{f_{X}}{r}\right)-\left(K_{Y}-D_{X}\right)+A_{2 D Y} \frac{\theta_{Y}^{\beta_{Y 2}}}{\theta_{X}^{\beta_{Y 2}}} \hat{v}_{S S X}^{\beta_{Y 2}} .
\end{aligned}
$$

Solutions to the option coefficients are similarly obtainable from the two associated smoothpasting conditions:

$$
\left[\begin{array}{l}
A_{1 X} \\
A_{2 X}
\end{array}\right]=\left[\begin{array}{l}
\mathrm{d}^{-1}\left(c_{4} \hat{v}_{D D X}^{\beta_{X 2}}-c_{3} \hat{v}_{S S X}^{\beta_{X 2}}\right) / \beta_{X 1} \\
\mathrm{~d}^{-1}\left(-c_{4} \hat{v}_{D D X}^{\beta_{X 1}}+c_{3} \hat{v}_{S S X}^{\beta_{X 1}}\right) / \beta_{X 2}
\end{array}\right],
$$

where

$$
\begin{aligned}
& c_{3}=-\frac{\hat{v}_{D D X}}{\delta+\theta_{X}}, \\
& c_{4}=\frac{\hat{v}_{S S X} \theta_{Y}}{\theta_{X}\left(\delta+\theta_{Y}\right)}-\frac{\hat{v}_{S S X}}{\delta+\theta_{X}}+\beta_{Y 2} A_{2 D Y} \frac{\theta_{Y}^{\beta_{Y 2}}}{\theta_{X}^{\beta_{Y 2}}} \hat{v}_{S S X}^{\beta_{Y 2}} .
\end{aligned}
$$

From (19) and (20), solution values for the two thresholds satisfy:

$$
\left.\begin{array}{r}
\hat{v}_{D D X}^{\beta_{X 2}}\left(\beta_{X 1} c_{2}-c_{4}\right)-\hat{v}_{S S X}^{\beta_{X 2}}\left(\beta_{X 1} c_{1}-c_{3}\right)=0 \\
-\hat{v}_{D D X}^{\beta_{X 1}}\left(\beta_{X 2} c_{2}-c_{4}\right)+\hat{v}_{S S X}^{\beta_{X 1}}\left(\beta_{X 2} c_{1}-c_{3}\right)=0
\end{array}\right\} .
$$

Solutions are usually obtainable through the use of numerical methods.

There are some conditions required in order to use the Décamps et al. (2006) adaptation for identifying a possible inaction region. Assuming a world of reduced output flows and a fully available appropriate technology, the technology $\mathrm{Y}$ would be implemented for an initial revenue $v_{X}>\hat{v}_{S X}$ as soon as $v_{X}$ hits the threshold $\hat{v}_{S X}$, provided $A_{2 S X}>A_{2 D X}$. However, if the appropriate technology is available after $v_{X}<\hat{v}_{S X}$, then the amended formulation (18) becomes obligatory. This does presume that the derived inaction region and solution values are feasible and plausible. To be feasible, $\hat{v}_{S S X}<\hat{v}_{S X}$, or otherwise the inaction region includes 
the stopping time for the optimal exercise of the appropriate technology, and to be plausible, $A_{1 X}, A_{2 X} \geq 0$, or otherwise the associated option is not value enhancing. Some of these conditions may not be met with particular sets of parameter values.

\subsection{Partly Deferred Divestment}

The rescaling switch from technology $X$ to $Y$ may not entail a full divestment, since some of the existing installation and infrastructure may be crucial to the successful implementation of $Y$. We denote by $\varphi$ the proportion of technology $X$ value divested at the switch, so $\varphi D_{X}$ is the value recovered from divesting the inessential element of $X$. The remainder $(1-\varphi) D_{X}$ is deferred and recovered (or paid) when $Y$ is divested, yielding a total $(1-\varphi) D_{X}+D_{Y}$. Although we constrain $0 \leq \varphi \leq 1$ in our numerical evaluations, $\varphi<0$ is possible for $\varphi D_{X}<0$ with $D_{X}>0$ or $\varphi D_{X}>0$ with $D_{X}<0$. The optimal switching threshold $\hat{v}_{S X(\varphi)}$ is obtained from the revised value matching relationship (12):

$$
\frac{\hat{v}_{S X(\varphi)}}{\delta+\theta_{X}}-\frac{f_{X}}{r}+A_{2 S X(\varphi)} \hat{v}_{S X(\varphi)}^{\beta_{X 2}}=\frac{\hat{v}_{S X(\varphi)} \theta_{Y}}{\theta_{X}\left(\delta+\theta_{Y}\right)}-\frac{f_{Y}}{r}-\left(K_{Y}-\varphi D_{X}\right)+A_{2 D Y(\varphi)} \frac{\theta_{Y}^{\beta_{Y 2}}}{\theta_{X}^{\beta_{Y Y}}} \hat{v}_{S X(\varphi)}^{\beta_{Y 2}} .
$$

The threshold $\hat{v}_{S X(\varphi)}$ and option coefficient $A_{2 S X(\varphi)}$ are determined in a similar way as before. Since the $Y$ divestment value is now $(1-\varphi) D_{X}+D_{Y}$, revising (13) yields:

$$
A_{2 D Y(\varphi)}=\left(\frac{(1-\varphi) D_{X}+D_{Y}+f_{Y} / r}{1-\beta_{Y 2}}\right)^{1-\beta_{Y 2}}\left(-\beta_{Y 2}\left(\delta+\theta_{Y}\right)\right)^{-\beta_{Y 2}} \text {. }
$$

In a similar way, we can modify (18) to determine the lower and upper thresholds for the inaction region, $\hat{v}_{D D X(\varphi)}, \hat{v}_{S S X(\varphi)}$, and the respective option coefficients, $A_{1 X(\varphi)}, A_{2 X(\varphi)}$, for the case of a partly deferred divestment. Then:

$$
\left.\begin{array}{l}
\frac{\hat{v}_{D D X(\varphi)}}{\delta+\theta_{X}}-\frac{f_{X}}{r}+A_{1 X(\varphi)} \hat{v}_{D D X(\varphi)}^{\beta_{X 1}}+A_{2 X(\varphi)} \hat{v}_{D D X(\varphi)}^{\beta_{X 2}}=\varphi D_{X}, \\
\frac{\hat{v}_{S S X(\varphi)}}{\delta+\theta_{X}}-\frac{f_{X}}{r}+A_{1 X(\varphi)} \hat{v}_{S S X(\varphi)}^{\beta_{X 1}}+A_{2 X(\varphi)} \hat{v}_{S S X(\varphi)}^{\beta_{X 2}} \\
=\frac{\hat{v}_{S S X(\varphi)} \theta_{Y}}{\theta_{X}\left(\delta+\theta_{Y}\right)}-\frac{f_{Y}}{r}-\left(K_{Y}-\varphi D_{X}\right)+A_{2 D Y(\varphi)} \frac{\theta_{Y}^{\beta_{Y 2}}}{\theta_{X}^{\beta_{Y 2}}} \hat{v}_{S S X(\varphi)}^{\beta_{Y}} .
\end{array}\right\}
$$

From (21): 


$$
\left.\begin{array}{r}
\hat{v}_{D D X(\varphi)}^{\beta_{X 2}}\left(\beta_{X 1} c_{2(\varphi)}-c_{4(\varphi)}\right)-\hat{v}_{S S X(\varphi)}^{\beta_{X 2}}\left(\beta_{X 1} c_{1(\varphi)}-c_{3(\varphi)}\right)=0 \\
-\hat{v}_{D D X(\varphi)}^{\beta_{X 1}}\left(\beta_{X 2} c_{2(\varphi)}-c_{4(\varphi)}\right)+\hat{v}_{S S X(\varphi)}^{\beta_{X 1}}\left(\beta_{X 2} c_{1(\varphi)}-c_{3(\varphi)}\right)=0
\end{array}\right\}
$$

where:

$$
\begin{aligned}
\mathrm{d}_{(\varphi)} & =\hat{v}_{D D X(\varphi)}^{\beta_{X 2}} \hat{v}_{S S X(\varphi)}^{\beta_{X 1}}-\hat{v}_{D D X(\varphi)}^{\beta_{X 1}} \hat{v}_{S S X(\varphi)}^{\beta_{X 2}}, \\
c_{1(\varphi)} & =\varphi D_{X}+\frac{f_{X}}{r}-\frac{\hat{v}_{D D X(\varphi)}}{\delta+\theta_{X}} \\
c_{2(\varphi)} & =\left(\frac{\hat{v}_{S S X(\varphi)} \theta_{Y}}{\theta_{X}\left(\delta+\theta_{Y}\right)}-\frac{f_{Y}}{r}\right)-\left(\frac{\hat{v}_{S S X(\varphi)}}{\delta+\theta_{X}}-\frac{f_{X}}{r}\right)-\left(K_{Y}-\varphi D_{X}\right)+A_{2 D Y(\varphi)} \frac{\theta_{Y}^{\beta_{Y 2}}}{\theta_{X}^{\beta_{Y 2}}} \hat{v}_{S S X(\varphi)}^{\beta_{Y Y}}, \\
c_{3(\varphi)} & =-\frac{\hat{v}_{D D X(\varphi)}}{\delta+\theta_{X}}, \\
c_{4(\varphi)} & =\frac{\hat{v}_{S S X(\varphi)} \theta_{Y}}{\theta_{X}\left(\delta+\theta_{Y}\right)}-\frac{\hat{v}_{S S X(\varphi)}}{\delta+\theta_{X}}+\beta_{Y 2} A_{2 D Y(\varphi)} \frac{\theta_{Y}^{\beta_{Y 2}}}{\theta_{X}^{\beta_{Y 2}}} \hat{v}_{S S X(\varphi)}^{\beta_{Y 2}} .
\end{aligned}
$$

Also, from (19):

$$
\left[\begin{array}{l}
A_{1 X(\varphi)} \\
A_{2 X(\varphi)}
\end{array}\right]=\left[\begin{array}{l}
\mathrm{d}_{(\varphi)}^{-1}\left(c_{2(\varphi)} \hat{v}_{D D X(\varphi)}^{\beta_{X 2}}-c_{1(\varphi)} \hat{v}_{S S X(\varphi)}^{\beta_{X 2}}\right) \\
\mathrm{d}_{(\varphi)}^{-1}\left(-c_{2(\varphi)} \hat{v}_{D D X X(\varphi)}^{\beta_{X 1}}+c_{1(\varphi)} \hat{v}_{S S X(\varphi)}^{\beta_{X 1}}\right)
\end{array}\right] .
$$

\section{Numerical Illustrations}

Further insights into the behaviour of the solution are obtained through numerical sensitivity analysis. The simulations are in the main generated from the base case, presented in Table 2 . The conventional technology is seen to be more expensive because of the greater periodic operating expense but with a greater depletion rate due to $\theta_{X}>\theta_{Y}$. At divestment, both technologies incur decommissioning costs (or negative divestment values). The values in Table 2 are selected so $f_{X}>-r D_{X}, f_{Y}>-r D_{Y}$ and $f_{X}>r\left(K_{Y}-D_{X}\right)+f_{Y}$ are satisfied. 
Table 2. Base Case Values

$\begin{array}{llr}\text { Parameter } & \text { Symbol } & \text { Value } \\ \text { Risk-free rate } & r & 5.0 \% \\ \text { Oil convenience yield } & \delta & 3.0 \% \\ \text { Oil price volatility } & \sigma & 30.0 \% \\ \text { Depletion rate for } X & \theta_{X} & 5.0 \% \\ \text { Periodic operating cost for } X & f_{X} & 1600 \\ \text { Divestment value for } X & D_{X} & -2500 \\ \text { Depletion rate for } Y & \theta_{Y} & 3.0 \% \\ \text { Switch investment cost to } Y & K_{Y} & 6000 \\ \text { Periodic operating cost for } Y & f_{Y} & -120 \\ \text { Divestment value for } Y & D_{Y} & \\ \text { Case Solution } & & \end{array}$

\subsection{Base Case Solution}

The relevant option power parameters for the two technologies are evaluated from (6) as $\beta_{X 2}=-0.5104$ and $\beta_{Y 2}=-0.6073$, with $\beta_{X 2}>\beta_{Y 2}$ as expected. We first consider the solution values for the separate formulation, presented in Table 3. This reveals the preferred policy to be (b) by having the greater option coefficient. Selecting policy (b) maximises the total oil recovery and extends the life of the field, since for an identical oil price, the residual volume for the depleted field is less under $Y$ than for under $X$ because $\hat{v}_{D Y} \theta_{X} / \theta_{Y}=222.173<\hat{v}_{D X}$. The effect of excluding $Y$ divestment optionality is to increase the switch threshold but decrease the option coefficient, thereby making policy (b) less valuable but exercised earlier.

Table 3: Solution for the Separate Formulation using Base Case Values

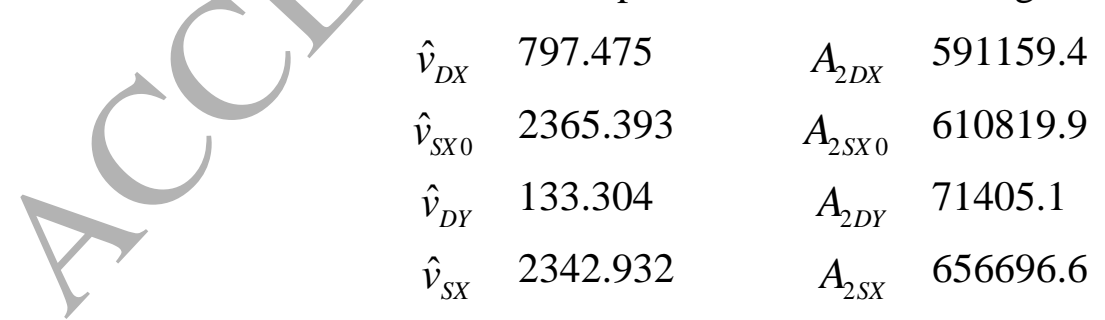

The divestment thresholds and option coefficients under $X, Y, \hat{v}_{D X}, A_{2 D X}, \hat{v}_{D Y}, A_{2 D Y}$ are obtained using the base case values from (9) and (10), respectively. The switch thresholds and option coefficients, in the absence and presence of $Y$ divestment optionality, $A_{2 D Y}=0$ (with threshold subscript 0) and $A_{2 D Y}>0, \hat{v}_{S X 0}, A_{2 S X 0}, \hat{v}_{S X}, A_{2 S X}$ are obtained from (15) and (16), respectively. 
When the initial revenue is less than the threshold $v_{X}<\hat{v}_{S X}$, the formulation is amended by evaluating policy (a) and (b) jointly to generate the inaction region. This is presented in Table 4, for $Y$ divestment optionality absent or present. In line with Décamps et al. (2006), we find that when $Y$ divestment optionality is present:

$$
\hat{v}_{S X} \geq \hat{v}_{S S X}>\hat{v}_{D X} \geq \hat{v}_{D D X}
$$

and a similar expression for when absent. For $v_{X}<\hat{v}_{S X}$, policy (a) and (b) stopping regions are $\left(0, \hat{v}_{D D X}\right)$ and $\left(\hat{v}_{S S X}, \hat{v}_{S X}\right)$, respectively, and the inaction region is $\left(\hat{v}_{D D X}, \hat{v}_{S S X}\right)$. The effect of excluding $Y$ divestment optionality makes policy (b) less attractive and causes policy (b) stopping region to shrink quite significantly, but both policy (a) stopping region and the inaction region to extend. Further, since all the option coefficients are positive, the results are both feasible and plausible. The amended decision rule becomes:

$$
\begin{array}{ll}
v_{X}>\hat{v}_{S X} & \text { Maintain continued extraction under } X \\
\hat{v}_{S X} \geq v_{X}>\hat{v}_{S S X} & \text { Switch to policy (b) } \\
\hat{v}_{S S X} \geq v_{X}>\hat{v}_{D D X} & \text { Maintain continued extraction under } X \\
\hat{v}_{D D X} \geq v_{X} & \text { Switch to policy (a) }
\end{array}
$$

Table 4. Solution for the Joint Formulation using Base Case Values

$Y$ divestment optionality absent, $A_{2 D Y}=0$

$\begin{array}{llll}\hat{v}_{D D X 0} & 791.341 & A_{2 X 0} & 589847.0 \\ \hat{v}_{S S X 0} & 2106.832 & A_{1 X 0} & 2.111 \mathrm{E}-05\end{array}$

$Y$ divestment optionality present, $A_{2 D Y}>0$

$$
\begin{array}{llll}
\hat{v}_{D D X} & 766.780 & A_{2 X} & 584420.0 \\
\hat{v}_{S S X} & 1588.065 & A_{1 X} & 1.134 \mathrm{E}-04
\end{array}
$$

The thresholds specifying the inaction region, $\left(\hat{v}_{D D X}, \hat{v}_{S S X}\right)$, are evaluated from (21) using the base case values and the policy (a) and (b) option coefficients, $A_{2 X}, A_{1 X}$, from (19) or (20).

Obviously, the particular real option evaluation method matters, since the divestment threshold is lower from 797 (separate approach) to 767 (joint analysis), the thresholds justifying the switch to the lower cost technology are quite different. Also, the possibility of the option to divest from that lower cost technology reduces the divestment threshold even under the joint method. 


\subsection{Variations in the Variables}

Variations in $f_{X}, f_{Y}, D_{X}, D_{Y}, K_{Y}$ have the expected impact on the solution obtained from the separate formulation. Assuming $v_{X}>\hat{v}_{S X}$ and policy (b) to have the greater option coefficient, Table 5 illustrates the impact of individual changes on the relevant thresholds and option values whilst maintaining the other base case values. A positive change in $f_{X}$ makes continued extraction under $X$ less attractive. but policy (a) and (b) more attractive. This is reflected in both policy (a) and (b) having greater thresholds indicating an earlier exercise and greater option coefficients. A positive change in $f_{Y}$ has no impact on policy (a), but makes policy (b) less attractive. It results in a reduction in the switch threshold thereby deferring its exercise and in the option coefficient, making it less valuable. The impact of a positive change in $D_{X}$ is to make continued extraction under $X$ less attractive but policy (a) more attractive. This is reflected in a greater threshold $\hat{v}_{D X}$ and option coefficient $A_{2 D X}$, but a secondary effect on policy (b) behaviour is also evident due to its influence on $K_{Y}-D_{X}$. A positive change in $D_{Y}$ makes policy (b) more attractive because of the termination option, but it has no impact on the behaviour of policy (a). Finally, a reduction in $K_{Y}$ enhances policy (b), raising the threshold and the option value whilst having no effect on policy (a).

The stopping regions are deriyed from the joint formulation for $v_{X}<\hat{v}_{S X}$. The impact of the individual changes is reported in Table 6, which reveals that the Décamps et al. (2006) condition continues to hold. A positive increase in $f_{X}$ implies a loss of attractiveness in continued extraction under $X$ while there are gains for both policy (a) and (b) that are reflected in increased option coefficients. Also, the stopping regions for policy (a) and (b) widen while the inaction region narrows. This picture of a wider policy (a) and (b) stopping region but a harrower inaction region is repeated to a greater or lesser extent whenever changes for the remaining four variables signal an increase in policy (a) and (b) attractiveness relative to continuance. The effect of an $D_{X}$ increase, which enhances the attractiveness of both policy (a) and (b), is to widen their stopping regions, while a $f_{Y}, K_{Y}$ decrease or $D_{Y}$ increase, which enhances the attractiveness of only policy (b), is to produce a widening for policy (b) and a narrowing for (a), although the magnitude of the $D_{Y}$ impact is modest. 
Table 5. Separate Formulation Impact of Variations in the Variables on the Thresholds and Option Coefficients

\begin{tabular}{llrrrr} 
& & $\hat{v}_{D X}$ & $\hat{v}_{S X}$ & $A_{2 D X}$ & $A_{2 S X}$ \\
\hline \multicolumn{2}{l}{ Base case } & 797.48 & 2342.93 & $5.91159 \mathrm{E}+05$ & $6.56697 \mathrm{E}+05$ \\
I & $f_{X}=1680$ & 840.73 & 2560.38 & $6.40251 \mathrm{E}+05$ & $7.42595 \mathrm{E}+05$ \\
& $f_{X}=1520$ & 754.22 & 2125.30 & $5.43409 \mathrm{E}+05$ & $5.74778 \mathrm{E}+05$ \\
II & $f_{Y}=315$ & 797.48 & 2300.24 & $5.91159 \mathrm{E}+05$ & $6.44857 \mathrm{E}+05$ \\
& $f_{Y}=285$ & 797.48 & 2385.52 & $5.91159 \mathrm{E}+05$ & $6.68806 \mathrm{E}+05$ \\
III $\quad D_{X}=-2625$ & 794.10 & 2325.94 & $5.87380 \mathrm{E}+05$ & $6.50151 \mathrm{E}+05$ \\
& $D_{X}=-2375$ & 800.85 & 2359.93 & $5.94947 \mathrm{E}+05$ & $6.63267 \mathrm{E}+05$ \\
IV $\quad D_{Y}=-126$ & 797.48 & 2342.97 & $5.91159 \mathrm{E}+05$ & $6.56621 \mathrm{E}+05$ \\
& $D_{Y}=-114$ & 797.48 & 2342.90 & $5.91159 \mathrm{E}+05$ & $6.56772 \mathrm{E}+05$ \\
V & $K_{Y}=6300$ & 797.48 & 2302.14 & $5.91159 \mathrm{E}+05$ & $6.41028 \mathrm{E}+05$ \\
& $K_{Y}=5700$ & 797.48 & 2383.72 & $5.91159 \mathrm{E}+05$ & $6.72505 \mathrm{E}+05$ \\
\hline
\end{tabular}

The threshold and option coefficient for policy (a) $\hat{v}_{D X}, A_{2 D X}$ are determined from (9) and (10), respectively, and for policy (b) $\hat{v}_{S X}, A_{2 S X}$ from (15) and (16), respectively. The impacts are evaluated for a 5\% increase and decrease in the base case value for I: operating charge under $X, f_{X}$, Il operating charge under $Y, f_{Y}$, III: divestment value for $X$, $D_{X}$, IV: divestment value for $Y, D_{Y}$, and V: switching cost to $Y, K_{Y}$. The base case solution is given as a benchmark.

Table 6. Joint Formulation Impact of Variations in the Variables on the Lower and Upper Thresholds and Corresponding Option Coefficients

\begin{tabular}{|c|c|c|c|c|}
\hline & $\hat{v}_{D D X}$ & $\hat{v}_{S S X}$ & $A_{2 X}$ & $A_{1 X}$ \\
\hline Bas & 766.78 & 1588.07 & $5.84420 \mathrm{E}+05$ & $1.13156 \mathrm{E}-04$ \\
\hline I & 789.49 & 1506.45 & $6.28476 \mathrm{E}+05$ & $1.77259 \mathrm{E}-04$ \\
\hline & 740.79 & 1707.93 & $5.40591 \mathrm{E}+05$ & $5.33886 \mathrm{E}-05$ \\
\hline$f_{Y}=315$ & 773.09 & 1655.23 & $5.85841 \mathrm{E}+05$ & 8.83042E-05 \\
\hline & 760.02 & 1525.51 & $5.82877 \mathrm{E}+05$ & $1.40779 \mathrm{E}-04$ \\
\hline$D_{X}=-2625$ & 764.87 & 1595.75 & $5.80987 \mathrm{E}+05$ & $1.08310 \mathrm{E}-04$ \\
\hline$D_{X}=-2375$ & 768.67 & 1580.60 & $5.87855 \mathrm{E}+05$ & $1.18027 \mathrm{E}-04$ \\
\hline$D_{Y}=-126$ & 766.84 & 1588.84 & $5.84433 \mathrm{E}+05$ & $1.12928 \mathrm{E}-04$ \\
\hline$D_{Y}=-114$ & 766.72 & 1587.29 & $5.84407 \mathrm{E}+05$ & $1.13383 \mathrm{E}-04$ \\
\hline$K_{Y}=6300$ & 775.63 & 1696.99 & $5.86408 \mathrm{E}+05$ & $7.85368 \mathrm{E}-05$ \\
\hline$K_{Y}=5700$ & 756.87 & 1489.70 & $5.82152 \mathrm{E}+05$ & 1.53984E-04 \\
\hline
\end{tabular}

The thresholds specifying the inaction region, $\left(\hat{v}_{D D X}, \hat{v}_{S S X}\right)$, are evaluated from (21) using the base case values and the policy (a) and (b) option coefficients, $A_{2 X}, A_{1 X}$, from (19) or (20). The impacts are evaluated for a $5 \%$ increase and 
decrease in the base case value for I: operating charge under $X, f_{X}$, II operating charge under $Y, f_{Y}$, III: divestment value for $X, D_{X}$, IV: divestment value for $Y, D_{Y}$, and V: switching cost to $Y, K_{Y}$. The base case solution is given as a benchmark.

A comparison of the two formulations reveals that for revenue levels close to the divestment thresholds, an $f_{X}$ increase due to government requirements (or removing subsidies) or unanticipated maintenance may be sufficient to trigger divestment under the Dixit model, but not necessarily under the Décamps model. In contrast, a $f_{X}$ decrease due to government subsidies or tax reliefs or cost sharing across contiguous fields has the opposite effect and defers divestment. The impact of lower decommissioning costs arising from tax credits or subsidies makes divestment only slightly more likely. A lower investment switching cost due to a tax credit or subsidy makes switching more attractive and divestment less attractive.

\subsection{Variations in Volatility}

A volatility increase for a standard investment-style model causes a threshold increase thereby deferring exercise and enhancing the option value, Dixit and Pindyck (1994). For a divestment-switching joint formulation, a volatility increase also causes a switching threshold increase, which results in an earlier exercise, but it is accompanied by a reduced option value because continuance has lost attractiveness. The impact of volatility variations on separately formulated derived solutions for policy (a) and (b) are presented in Figure 3, illustrating their thresholds, and Figure 4, illustrating the ratio of their option coefficients, evaluated using the base case values except for the variations in volatility. These figures show policy (b) is preferred provided $\sigma \leq 0.38$. If $\sigma \geq 0.39$, then policy (a) is preferred because of its greater option coefficient despite having a lower threshold. In view of this, we confine our investigation of the effect of volatility changes on the inaction region to the range $\sigma \leq 0.38$.

Figure 3: Optimal Thresholds for Policies (a) and (b) Separate Formulation 
For the various price volatilities, the thresholds for policy (a) $\hat{v}_{D X}$ (divest) and policy (b) $\hat{v}_{S X}$ (switch) are determined from (9) and (15), respectively. Some illustrated threshold values are shown below.

\begin{tabular}{lrr}
$\sigma$ & $\hat{v}_{D X}$ & $\hat{v}_{S X}$ \\
\hline 0.005 & 1474.39 & 4373.17 \\
0.05 & 1419.36 & 4209.70 \\
0.10 & 1295.49 & 3839.68 \\
0.15 & 1156.23 & 3420.74 \\
0.20 & 1023.32 & 3020.06 \\
0.25 & 903.32 & 2659.37 \\
0.30 & 797.48 & 2342.93 \\
0.35 & 705.12 & 2068.46 \\
0.40 & 624.95 & 1831.48 \\
0.45 & 555.51 & 1627.11 \\
0.50 & 495.37 & 1450.71 \\
\hline
\end{tabular}

Figure 4: Option Coefficient Ratio for Policy (b) relative to Policy (a)

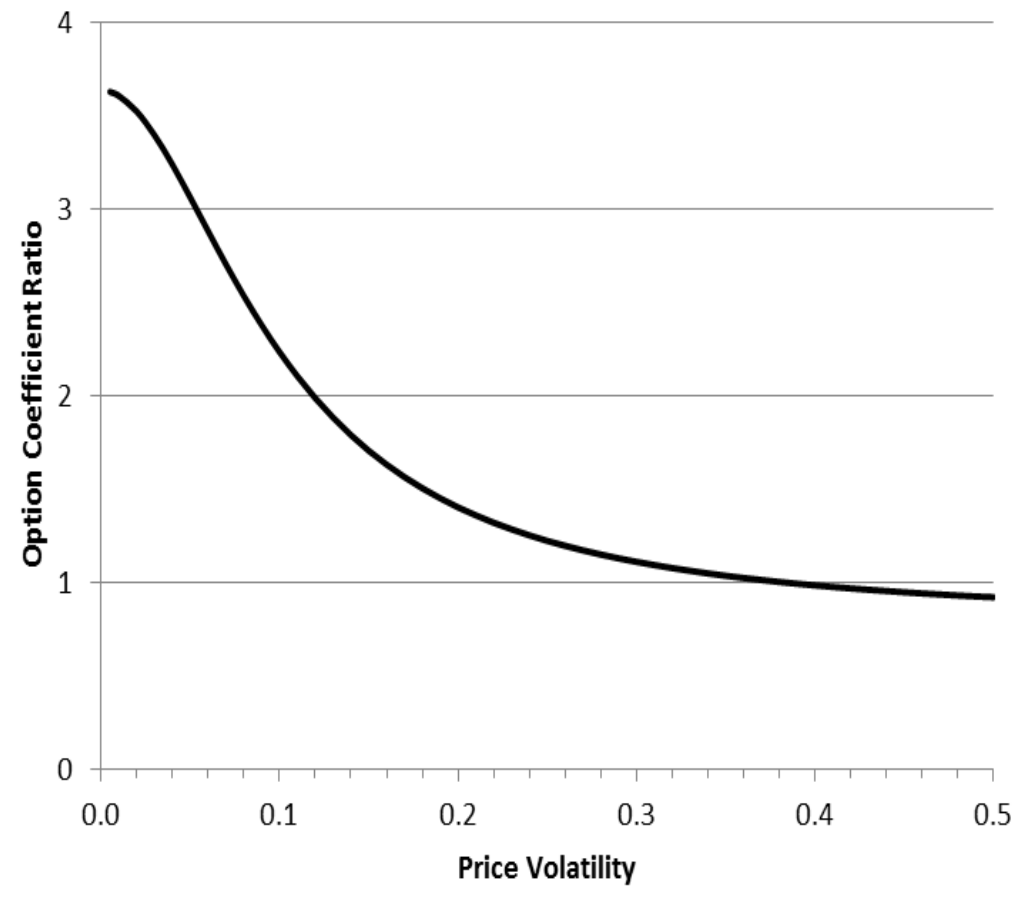

For the various price volatilities, the option coefficient for policy (a) $A_{2 D X}$ and (b) $A_{2 S X}$ are determined from (10) and (16), respectively. Some illustrated option coefficient values are shown below.

\begin{tabular}{lrrr}
$\sigma$ & $A_{2 D X}$ & $A_{2 S X}$ & $A_{2 S X} / A_{2 D X}$ \\
\hline 0.005 & $2.0860 \mathrm{E}+09$ & $7.5620 \mathrm{E}+09$ & 3.6251 \\
0.05 & $6.7082 \mathrm{E}+08$ & $2.0529 \mathrm{E}+09$ & 3.0603 \\
0.10 & $8.1632 \mathrm{E}+07$ & $1.8232 \mathrm{E}+08$ & 2.2335 \\
0.15 & $1.3168 \mathrm{E}+07$ & $2.2460 \mathrm{E}+07$ & 1.7056 \\
0.20 & $3.3674 \mathrm{E}+06$ & $4.7240 \mathrm{E}+06$ & 1.4029 \\
0.25 & $1.2396 \mathrm{E}+06$ & $1.5164 \mathrm{E}+06$ & 1.2234 \\
0.30 & $5.9116 \mathrm{E}+05$ & $6.5670 \mathrm{E}+05$ & 1.1109
\end{tabular}




\begin{tabular}{llll}
0.35 & $3.3828 \mathrm{E}+05$ & $3.5065 \mathrm{E}+05$ & 1.0366 \\
0.36 & $3.0771 \mathrm{E}+05$ & $3.1534 \mathrm{E}+05$ & 1.0248 \\
0.37 & $2.8125 \mathrm{E}+05$ & $2.8515 \mathrm{E}+05$ & 1.0139 \\
0.38 & $2.5824 \mathrm{E}+05$ & $2.5918 \mathrm{E}+05$ & 1.0037 \\
0.39 & $2.3811 \mathrm{E}+05$ & $2.3672 \mathrm{E}+05$ & 0.9942 \\
0.40 & $2.2042 \mathrm{E}+05$ & $2.1717 \mathrm{E}+05$ & 0.9853 \\
0.41 & $2.0482 \mathrm{E}+05$ & $2.0009 \mathrm{E}+05$ & 0.9769 \\
0.42 & $1.9099 \mathrm{E}+05$ & $1.8509 \mathrm{E}+05$ & 0.9691 \\
0.43 & $1.7868 \mathrm{E}+05$ & $1.7186 \mathrm{E}+05$ & 0.9618 \\
0.44 & $1.6769 \mathrm{E}+05$ & $1.6013 \mathrm{E}+05$ & 0.9549 \\
0.45 & $1.5784 \mathrm{E}+05$ & $1.4970 \mathrm{E}+05$ & 0.9485 \\
0.50 & $1.2118 \mathrm{E}+05$ & $1.1164 \mathrm{E}+05$ & 0.9212 \\
\hline
\end{tabular}

When $v_{X}<\hat{v}_{S X}$, the stopping regions for policy (a) and (b) are obtained from the joint formulation. Figures 5 and 6 illustrate, respectively, the thresholds and option coefficients for the volatility variations $0.18 \leq \sigma \leq 0.38$. Figure 5 reveals that the Décamps et al. (2006) conditions hold for the particular range of volatilities, given the other base parameter values. The thresholds $\hat{v}_{S X}, \hat{v}_{D X}, \hat{v}_{D D X}$ are decreasing while $\hat{v}_{S S X}$ is an increasing function of volatility, implying that volatility increases produce a narrowing of the policy (b) stopping region to zero but a widening of the inaction region until $\hat{v}_{D D X}=\hat{v}_{D X}$ and $\hat{v}_{S S X}=\hat{v}_{S X}$ at $\sigma=0.38$. Further, at $\sigma=0.38$, the separately formulated option values for policy (a) and (b) and the jointly formulated option value for policy (a) are all equal. When coefficients are equal, shown in Figure 6 at $\sigma=.38$, the owner is indifferent between the two policies but selects policy (b) if $v_{X}=\hat{v}_{S X}=\hat{v}_{S S X}$, policy (a) if $v_{X} \leq \hat{v}_{D X}=\hat{v}_{D D X}$, and waits if otherwise. On the other hand, if $\sigma>0.38$, the option coefficient $A_{1 X}<0$ making the solution implausible and $\hat{v}_{S S X}>\hat{v}_{S X}$ making the solution infeasible, violating the Décamps et al. (2006) conditions. Since policy (a) has greater option value despite a lower threshold, policy (a) is treated as the preferred alternative for $\sigma>0.38$.

There is no apparent numerical solution ${ }^{4}$ to (21) for low volatility such as $\sigma<0.18$, which is reflected in the terminated range for Figures 5 and 6 . This is probably because of errors being

\footnotetext{
${ }^{4}$ The calculations are computed using Mathematica $\bigodot$ Version 11.3. Errors are obtained when the numerical solutions to (21) are substituted into the value-matching relationship (18) and the associated smooth-pasting conditions. As an illustration, for $\sigma=0.17$, the errors following the substitution for the respective valuematching relationships are $-8.01 \times 10^{-11},-3.84 \times 10^{-11}$ and for the smooth-pasting conditions $-4.16,-13.44$. Also $A_{1 X}=8.58 \times 10^{-10}$. The errors in calculation are interpreted as being due to the presence of very small numbers in computing some of the expressions rather than to a mathematical singularity. We have also repeated these calculations using another numerical method, which replicates Figures 5 and 6 , and also shows that the $\mathrm{A}_{1 \mathrm{X}}$ option coefficients become tiny with low volatility and negative with high volatility, violating the Décamps
} 
introduced by multiplying a very small number like $A_{1 X}$ with very large number like $\hat{v}_{S S X}^{\beta_{X 1}}, \hat{v}_{D D X}^{\beta_{X 1}}$, rather than due to implausibility. Despite the computational difficulties, we can make inferences as the volatility declines to zero. Decreases in volatility produce a widening of the policy (b) stopping region but a narrowing of the inaction region until the inaction region disappears for $\sigma=0$ owing to the absence of uncertainty. At this point, $\hat{v}_{D D X}=\hat{v}_{S S X}$. By making this substitution in (18), then it follows that $\hat{v}_{D D X}=\hat{v}_{S S X}=1200$, which implies that for $v_{X}<\hat{v}_{S X}$, the stopping regions for policy (a) and (b) are $\left(\hat{v}_{S X}, \hat{v}_{S S X}\right),\left(\hat{v}_{S S X}, 0\right)$, respectively, while the inaction region is a null set. In addition to these computational issues, Bobtcheff and Villeneuve (2010) note that joint formulation may not be suitable for all parameter values and policy alternatives.

Figure 5: Optimal Thresholds for Price Volatility Variations

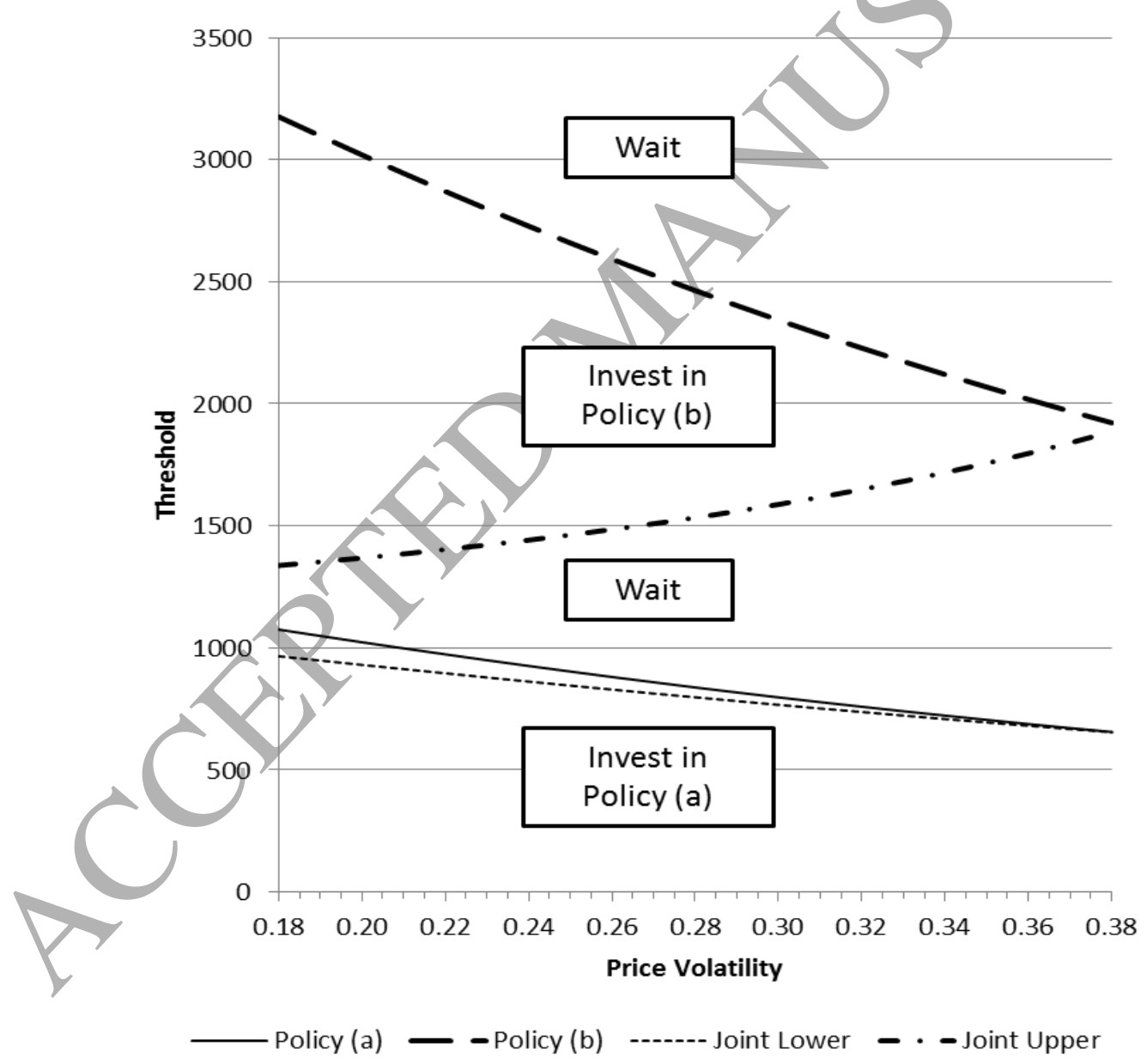

For the various price volatilities, the threshold policy (a) $\hat{v}_{D X}$ is found from (9), for (b) $\hat{v}_{S X}$ from (15), the thresholds specifying the inaction region, joint lower, joint upper $\left(\hat{v}_{D D X}, \hat{v}_{S S X}\right)$ from (21), using the base case values except for $\sigma$.

et al. (2006) conditions using these base case parameter values. Both sets of numerical solutions are available from the authors. 
The invest in policy (b) stopping region is $\left(\hat{v}_{S S X}, \hat{v}_{S X}\right)$, the invest in policy (a) stopping regions is $\left(0, \hat{v}_{D D X}\right)$, and the two waiting regions are $\left(\infty, \hat{v}_{S X}\right)$ and $\left(\hat{v}_{D D X}, \hat{v}_{S S X}\right)$. Some illustrated threshold values are shown below.

\begin{tabular}{lrrrc}
$\sigma$ & $\hat{v}_{D X}$ & $\hat{v}_{S X}$ & $\hat{v}_{D D X}$ & $\hat{v}_{S S X}$ \\
\hline 0.18 & 1075.12 & 3176.17 & 965.77 & 1337.59 \\
0.20 & 1023.32 & 3020.06 & 930.60 & 1368.48 \\
0.22 & 973.63 & 2870.52 & 896.02 & 1403.10 \\
0.24 & 926.19 & 2727.97 & 862.24 & 1441.83 \\
0.26 & 881.03 & 2592.56 & 829.39 & 1485.15 \\
0.28 & 838.14 & 2464.27 & 797.55 & 1533.66 \\
0.30 & 797.48 & 2342.93 & 766.78 & 1588.07 \\
0.32 & 758.98 & 2228.33 & 737.10 & 1649.26 \\
0.34 & 722.57 & 2120.20 & 708.51 & 1718.35 \\
0.36 & 688.16 & 2018.22 & 681.01 & 1796.74 \\
0.38 & 655.65 & 1922.09 & 654.59 & 1886.25
\end{tabular}

For a revenue level close to the divestment thresholds, a volatility increase makes divestment deferral less likely under the Dixit model, and somewhat less likely under the Décamps model. A volatility increase under the Décamps model produces a wider inaction region, and a greater hysteresis effect, but a narrower policy (b) stopping region. Policy (b) may not be attractive as the volatility increases, as the thresholds $\left(\hat{v}_{S X} \rightarrow \hat{v}_{S S X}\right)$, and the option coefficient $A_{1 X}$ becomes negative. 
Figure 6: Option Coefficient Values for Price Volatility Variations

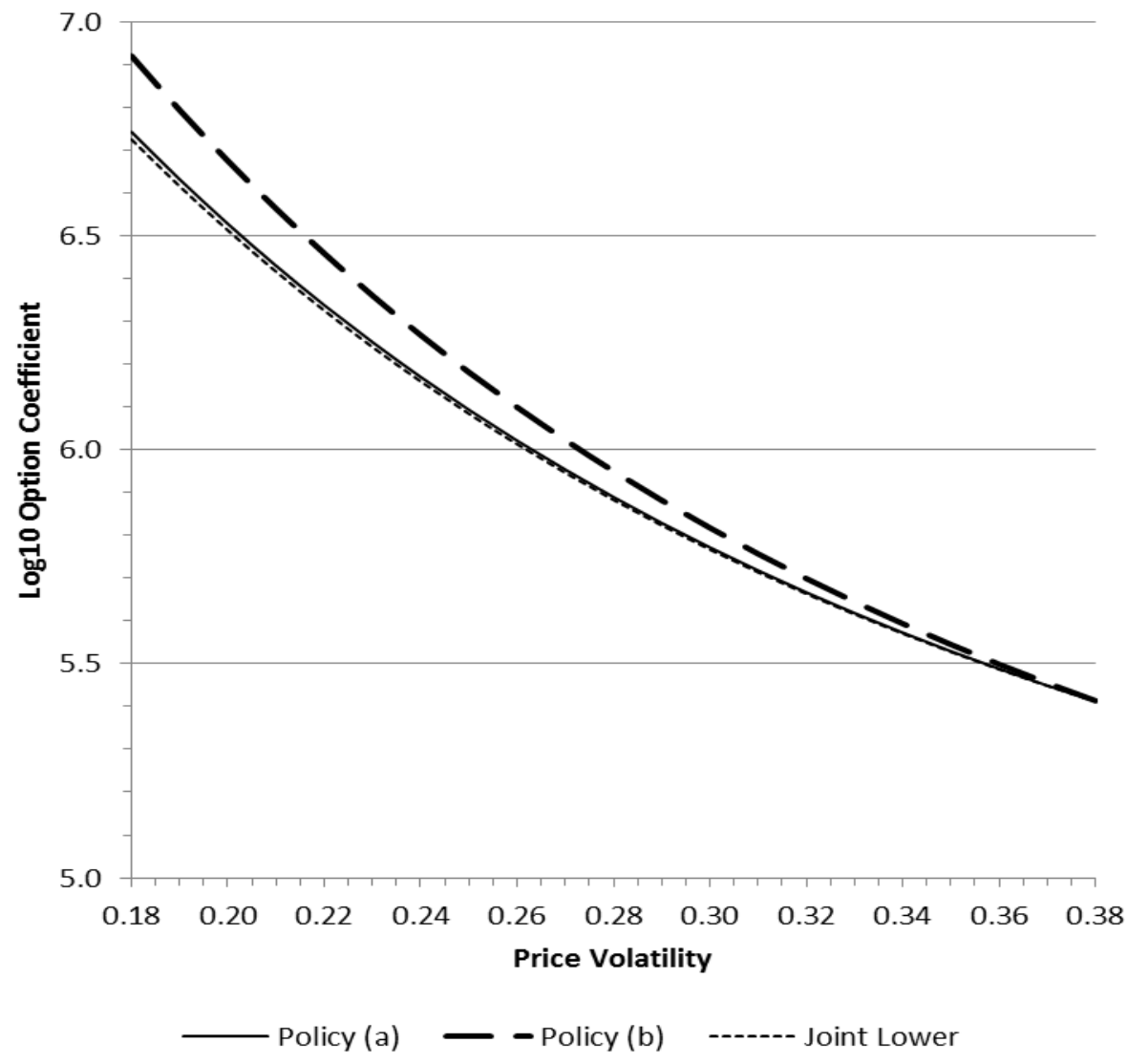

For the various price volatilities, the option coefficient for policy (a) $A_{2 D X}$ is found from (10), for (b) $A_{2 S X}$ from (16), and for the modified formulation, $A_{2 X}, A_{1 X}$, from (19) or (20), using the base case values except for $\sigma$. Some illustrated option coefficient values are shown below.

\begin{tabular}{rrrrr}
$\sigma$ & $A_{2 D X}$ & $A_{2 S X}$ & $A_{2 X}$ & $A_{1 X}$ \\
\hline 0.18 & $5.5250 \mathrm{E}+06$ & $8.3129 \mathrm{E}+06$ & $5.3061 \mathrm{E}+06$ & $5.4212 \mathrm{E}-09$ \\
0.20 & $3.3674 \mathrm{E}+06$ & $4.7240 \mathrm{E}+06$ & $3.2533 \mathrm{E}+06$ & $1.0253 \mathrm{E}-07$ \\
0.22 & $2.1753 \mathrm{E}+06$ & $2.8719 \mathrm{E}+06$ & $2.1132 \mathrm{E}+06$ & $9.3469 \mathrm{E}-07$ \\
0.24 & $1.4784 \mathrm{E}+06$ & $1.8518 \mathrm{E}+06$ & $1.4435 \mathrm{E}+06$ & $5.0859 \mathrm{E}-06$ \\
0.26 & $1.0500 \mathrm{E}+06$ & $1.2566 \mathrm{E}+06$ & $1.0300 \mathrm{E}+06$ & $1.8894 \mathrm{E}-05$ \\
0.28 & $7.7489 \mathrm{E}+05$ & $8.9119 \mathrm{E}+05$ & $7.6323 \mathrm{E}+05$ & $5.2218 \mathrm{E}-05$ \\
0.30 & $5.9116 \mathrm{E}+05$ & $6.5670 \mathrm{E}+05$ & $5.8442 \mathrm{E}+05$ & $1.1316 \mathrm{E}-04$ \\
0.32 & $4.6420 \mathrm{E}+05$ & $5.0024 \mathrm{E}+05$ & $4.6043 \mathrm{E}+05$ & $1.9707 \mathrm{E}-04$ \\
0.34 & $3.7381 \mathrm{E}+05$ & $3.9221 \mathrm{E}+05$ & $3.7185 \mathrm{E}+05$ & $2.7263 \mathrm{E}-04$ \\
0.36 & $3.0771 \mathrm{E}+05$ & $3.1534 \mathrm{E}+05$ & $3.0689 \mathrm{E}+05$ & $2.6949 \mathrm{E}-04$ \\
0.38 & $2.5824 \mathrm{E}+05$ & $2.5918 \mathrm{E}+05$ & $2.5813 \mathrm{E}+05$ & $7.1635 \mathrm{E}-05$ \\
\hline
\end{tabular}




\subsection{Variations in the Rate Parameters}

The impact of variations in $r, \delta, \theta_{X}, \theta_{Y}$ on the solution results obtained from the separate and joint formulations are illustrated in Appendix C. Generally, lower interest rates would motivate earlier divestment under both methods, and encourage adoption of the lower cost technology mostly under the Dixit method.

\subsection{Partly Deferred Divestment}

Because of the time value of money, policy (b) can be expected to enjoy a performance improvement whenever the divestment of $X$ is partly deferred to coincide with the divestment of $Y$. The proportion of $X$ that is divested at the exercise of policy (b) is denoted by $\varphi$, so the magnitude of the divestment deferral is related to $1-\varphi$. For $v_{X}>\hat{v}_{S X}$ and policy (b) having the greater option coefficient, Table 7 illustrates the effect of $\varphi$ variations, $\varphi=1.0,0.8, \ldots, 0.0$, on the thresholds and option coefficients pertaining to policy (b). Clearly, policy (a) remains unaffected. This reveals that as $\varphi$ decreases, both the $Y$ divestment threshold $\hat{v}_{D Y}$ and the divestment option coefficient $A_{2 D Y}$ decline. This suggests that $X$ divestment deferral postpones the timing of the subsequent $Y$ divestment, thereby prolonging the economic extraction of oil and reduces the value of the $Y$ divestment option. In contrast, a $\varphi$ reduction raises both the policy (b) threshold $\hat{v}_{S Y}$ and the switch option coefficient $A_{2 K Y}$. An increase in the amount of $X$ divestment that can be deferred makes not only the opportunity to switch to policy (b) more valuable but also advances the timing for switching optimally. This suggests that $X$ divestment deferral is beneficial for the various parties associated with extracting oil from depleted fields. The owner benefits from the increase in the residual oil reserve value while the suppliers of technology $Y$ are favoured by earlier sales for their innovation. The government may also be a beneficiary because of tax advantages from prolonged extraction as well as the tax saving from the divestment deferral. 
Table 7: The Effect Obtained Separately of $\varphi$ Variations on Policy (b)

\begin{tabular}{rrrrr}
$\varphi$ & $\hat{v}_{D Y}$ & $A_{2 D Y}$ & $\hat{v}_{S X}$ & $A_{2 S X}$ \\
\hline 1.0 & 133.30 & 71405.1 & 2342.93 & 656696.6 \\
0.8 & 121.97 & 61900.6 & 2413.85 & 677028.9 \\
0.6 & 110.63 & 52918.2 & 2484.50 & 698111.2 \\
0.4 & 99.30 & 44478.3 & 2554.87 & 719947.2 \\
0.2 & 87.96 & 36604.6 & 2624.98 & 742542.5 \\
0.0 & 76.63 & 29324.7 & 2694.83 & 765906.1 \\
\hline
\end{tabular}

The thresholds and option coefficients, $\hat{v}_{D Y}, \hat{v}_{S X}, A_{2 D Y}, A_{2 S X}$ are obtained from (22) and (23) using the base case values.

Similar kinds of results are obtained for the joint formulation when $v_{X}<\hat{v}_{S X}$ and policy (b) having the greater option coefficient, except that policy (a) is now affected. Table 8 illustrates the effect of $\varphi$ variations on the thresholds and option coefficients for both policy (a) and (b). As expected, a $\varphi$ decline produces a rise in the policy (b) option coefficient $A_{1 X(\varphi)}$ but a fall in the policy (a) option coefficient $A_{2 X(\phi)}$, because $X$ divestment deferral makes policy (b) relatively more attractive despite the $X$ divestment value for policy (a) remaining unaffected. Further, a $\varphi$ decline produces falls in both the lower and upper thresholds, $\hat{v}_{D D X}, \hat{v}_{S S X}$, respectively. This results in the expansion of the policy (b) stopping region $\left(\hat{v}_{S S X}, \hat{v}_{S X}\right)$ but the shrinkage of both the inaction region $\left(\hat{v}_{D D X}, \hat{v}_{S S X}\right)$ and the policy (a) stopping region $\left(0, \hat{v}_{D D X}\right)$. Again, this signifies that $X$ divestment deferral favours policy (b).

Table 8: The Effect Obtained Jointly of $\varphi$ Variations on Policies (a) and (b)

\begin{tabular}{rrrrr}
$\varphi$ & $\hat{v}_{D D X}$ & $\hat{v}_{S S X}$ & $A_{2 X}$ & $A_{1 X}$ \\
\hline 1.0 & 766.78 & 1588.07 & 584420.2 & $1.1316 \mathrm{E}-04$ \\
0.8 & 755.25 & 1485.99 & 581777.1 & $1.6087 \mathrm{E}-04$ \\
0.6 & 742.43 & 1393.59 & 578763.1 & $2.1770 \mathrm{E}-04$ \\
0.4 & 728.27 & 1308.65 & 575342.4 & $2.8543 \mathrm{E}-04$ \\
0.2 & 712.72 & 1229.55 & 571472.5 & $3.6638 \mathrm{E}-04$ \\
0.0 & 695.72 & 1155.04 & 567102.0 & $4.6359 \mathrm{E}-04$ \\
\hline
\end{tabular}


The thresholds and option coefficients $\hat{v}_{D D X}, \hat{v}_{S S X}, A_{2 X}, A_{1 X}$ are obtained from (25) and (26).

For policy (a), $D_{X}$ remains the same for any $\varphi$, since deferred divestment is only applicable for policy (b), not policy (a). A government measure enabling divestment to be partly deferred would entail a reduced $\varphi$ and a lower $D_{X}$ but only for policy (b). This results in making policy (b) relatively more attractive because of the reduced switching investment cost, which is reflected in a wider policy (b) stopping region, but a narrower policy (a) stopping region and a narrower inaction region. [Note that reducing the initial divestment cost defers, but does not eliminate, the decommissioning costs, so the results are not comparable with Table 6.]

\section{Conclusion and Discussion}

We formulate a real option model for determining the optimal rescale decision to switch from conventional to appropriate technology for a marginal mature off-shore oil installation. As an active field becomes increasingly marginalised, the original technologies are not economic and without a rescaling-contraction the residual oil in the reserve becomes economically trapped and inaccessible. Our model is formulated on oil price uncertainty described by a geometric Brownian motion process and a dynamic declining output volume, assumptions which enable a tractable analytical solution to be derived from the representation based on periodic revenue. The formulation incorporates divestment options not only because of the high cost in decommissioning an expended rig and its resulting impact on the divestment decision, but also because of its role in terminating an infinitely lived asset implied by the American perpetuity representation. However, the presence of abandonment affects whether a rescale can exist, since any feasible rescaling-contraction may have to be implemented while the oil reserve is active and not subsequent to divestment when the reserve is idle. Other assumptions made are typical for most other analytical real option models.

We have viewed the sequential investment/disinvestment decisions for a marginal oil field in several distinct ways. Initially, the evaluation of policy (a) of divesting the original installation and of policy (b) of switching to a lower cost technology is based on separate formulations, assuming that the threshold for the more valuable alternative has not yet been attained. Then we evaluate the joint formulation for policy (a) and (b), assuming that the 
threshold for the more valuable alternative has already been attained. Finally, we evaluate the consequences of partial divestment.

We assume a UK government assumes North Sea investors believe some (or all) of the above equations, a heroic assumption. We further assume that achieving a fundamental government goal of maximizing the economic recovery of oil from marginal fields is motivated by the early switching to a lower cost technology. Then, government should craft policies with the objective of stimulating a switch to policy (b) while at the same time deterring policy (a), the complete divestment of the incumbent technology. This entails measures designed to raise the policy (b) threshold $\hat{v}_{S X}$ and extend its stopping region $\left(\hat{v}_{S S X}, \hat{v}_{S X}\right)$, while simultaneously having the effect of reducing the divestment threshold $\hat{v}_{D X}$, shrinking the policy (a) stopping region $\left(0, \hat{v}_{D D X}\right)$, but widening the inaction region $\left(\hat{v}_{D D X}, \hat{v}_{S S X}\right)$. Our aim is to identify policy variables that affect these thresholds in the appropriate direction. Possibly $v_{X}, f_{X}, f_{Y}, D_{X}, D_{Y}, K_{Y}, \sigma_{p}$ can be altered some through government actions such as price guarantees, subsidies or tax reliefs, which could promote-MER.

Q1 Does the stochastic element, price volatility, matter?

Although oil price volatility is not directly controllable, governments can introduce structured price guarantees such as feed-in-tariffs or collars that are potentially capable of moderating the cash-flow volatility. Any volatility reduction has positive consequences for both policy (a) and (b) due to the increase in their thresholds $\hat{v}_{S X}, \hat{v}_{D X}$. But our illustration reveals that the effect on policy (b) is greater together with some evidence supporting an enlargement of the policy (b) stopping region.

Q2 Does the analytical method matter?

It is obvious that not only does the possibility of an alternative lower cost technology reduce the incentives for decommissioning in most cases, but considering the joint formation results in a significant reduction in the decommissioning threshold. However, depending on the current gross revenue, possible hysteresis is justified under the joint (and not the separate) formulation, which would not encourage adoption of lower cost technology, but could lead to 
MER. There are problems obtaining a feasible numerical solution in the joint formation at very high and very low volatilities, consistent with some theoretical restrictions in using the Decamps et al (2006) approach.

Q3 Does allowing for partial divestment defer decommissioning, or hasten the adoption of lower cost technologies, both promoting MER?

Switches to policy (b) become more attractive if government enacts concessions that permit decommissioning of technology $X$ to be partly deferred or favour switching technologies initiatives utilizing a high proportion of the assets underpinning technology $X$. Partial decommissioning with its lower $\varphi$ makes policy (b) more attractive by raising its switching threshold $\hat{v}_{S X}$ but policy (a) less attractive by lowering its switching threshold $\hat{v}_{D X}$. It also significantly widens the policy (b) stopping region $\left(\hat{v}_{S S X}, \hat{v}_{S X}\right)$

Q4 Are changes in other plausible government policies likely to lead to MER?

The other policy variables are selected from Table 2 . The significance of altering these policy variables is drawn from the tables and figures presented in Section 3. We do not consider the impact of changing items such as $\delta, \theta_{X}, \theta_{Y}$, since they are not subject to governmental influence $\left(\delta\right.$ is derived from the term structure of crude oil futures prices, and $\theta_{X}, \theta_{Y}$ are surely technical matters). Alternative royalty structures, subsidizing prices and expenses could change effective $v_{X}, f_{X}, f_{Y}$, although a more customary approach is to reduce corporate income taxes, which we have not explicitly considered. A subsidy may take the form of a preferential loan that lowers the interest rate. A reduced interest rate has the effect of increasing all the relevant thresholds for both policy (a) and (b), together with an enlarged policy (b) stopping region, but our illustration reveals the effect on policy (b) to be significantly greater.

A subsidy designed to lower $f_{X}$ would reduce both $\hat{v}_{S X}, \hat{v}_{D X}$, and result in prolonging the life of the incumbent technology but not necessarily in maximizing oil recovery. It may also inhibit innovation. A more favourable royalty structure would have a similar effect of 
deterring both switching to policy (b) and divestment. In contrast, a subsidy designed to lower $f_{Y}$ raises $\hat{v}_{S X}$ and lowers $\hat{v}_{S S X}, \hat{v}_{D D X}$, but has no effect on $\hat{v}_{D X}$.

A more attractive decommissioning allowance and investment subsidy each tend to favour technology $Y$, but in distinct ways. Although modest, an improved decommissioning allowance for technology $Y$ produces an enlarged policy (b) stopping region but a reduced policy (a) stopping region, but it has no effect on the switching threshold $\hat{v}_{S X}$. In contrast, a decommissioning allowance for technology $X$ leads to an increased $\hat{v}_{S X}$ and expanded stopping regions for policy (a) and (b). A plausible driver for motivating a switch to policy (b) is an investment subsidy. This has the effect of increasing the switching threshold $\hat{v}_{S X}$ and expanding the stopping region for policy (b), while narrowing that for policy (a).

In summary, a government has at its disposal a range of plausible policies capable of stimulating investors to switch from the incumbent oil extraction technology to one that is more appropriate. The illustrations demonstrate the successes or otherwise of the measures on offer are not identical but vary, often by a significant magnitude. There is no recommended preferred measure since it depends on the context, and each has to be assessed on its particular merits.

Our focus is on evaluating the effect of changes in government policy that engender more favourable thresholds and on earlier investment in the lower cost technology leading to MER. Maximizing the option values have not been cited as the primary objective for the government. However, if petroleum investors recognize the modelled real option values (and are willing and able to pay the government for these concession option values) the incentives that a government could offer for increasing such option values is another story. Finally, some of these policy instruments are relevant only over certain ranges, and our conclusions are based on $+/-5 \%$ from the base case except for $\sigma_{p}, \varphi$. Some sensitivity analysis for larger deviations from the base case show no changes in the sign of the affect, but the sensitivity magnitudes change.

The analysis can be extended in several ways. The model in its presented form investigates the comparative merits of a rescaling-contraction assuming known rescaling properties and 
the absence of contending alternatives. Many of the parameter values such as operating costs, rescaling and decommissioning costs are considered constant (although shown over some ranges in the tables and figures), which is not necessarily realistic. The increasing global prevalence of marginal fields may result in innovation with the possibility of the arrival of a more sophisticated appropriate technology with properties outperforming those studied here. This raises the question of whether the extractor should enact the rescale decision promptly or wait until the next innovation emerges. Also, the analysis is performed in isolation of economic alternatives such as gaining improvements through other production and cost efficiency gains. These developments should lead to a richer and more insightful representation of the economics of marginal fields.

Our analysis ignores competition, that is which operators should divest/switch first. Possibly some switching to a lower cost technology will "learn by doing", or learn by the success/faiure of others. Also, since the joint formulation may not produce feasible solutions for all ranges of parameter values, perhaps model improvements are warranted, covering even more policies.

Possible other applications of this model are rescaling shopping centres suffering from online retail to lower cost alternative uses, bookshops to dining and conceivably accommodation uses, licensed taxi systems to lower cost transportation arrangements, hotel booking systems to private accommodation sharing, and retraining mature workers (and educators) in a competitive context. However, decommissioning (retirement) costs, rates and output quality before/after rescaling will not be the same as in oil field depletion. Calibration of all parameter values for these models is a challenge for the future. 


\section{References}

Adkins, R., and D. Paxson. "Reciprocal energy switching options." Journal of Energy Markets 4 (2011a), 91-120.

- . "Renewing assets with uncertain revenues and operating costs." Journal of Financial and Quantitative Analysis 46 (2011b), 785-813.

- . "The Tourinho model: Neglected nugget or a receding relic?" The European Journal of Finance 19 (2013), 604-624.

-. "Replacement decisions with multiple stochastic values and depreciation." European Journal of Operational Research 257 (2017), 174-184.

Bjerksund, P., and S. Ekern. "Managing Investment Opportunities under Price Uncertainty: From "Last Chance" to "Wait and See" Strategies." Financial Management 19 (1990), 65-83.

Bobtcheff, C., and S. Villeneuve. "Technology choice under several uncertainty sources." European Journal of Operational Research 206 (2010), 586-600.

Brennan, M. J., and E. S. Schwartz. "Evaluating natural resource investments." Journal of Business 58 (1985), 135-157.

Chorn, L. G., and S. Shokhor. "Real options for risk management in petroleum development investments." Energy Economics 28 (2006), 489-505.

Chronopoulos, M., V. Hagspiel, and S.-E. Fleten. "Stepwise investment and capacity sizing under uncertainty." OR Spectrum 39 (2017), 447-472.

Chronopoulos, M., and S. Lumbreras. "Optimal regime switching under risk aversion and uncertainty." European Journal of Operational Research 256 (2017), 543-555.

Chronopoulos, M., and A. Siddiqui. "When is it better to wait for a new version? Optimal replacement of an emerging technology under uncertainty." Annals of Operations Research 235 (2015), 177-201.

Compernolle, T., K. Welkenhuysen, K. Huisman, K. Piessens, and P. Kort. "Off-shore enhanced oil recovery in the North Sea: The impact of price uncertainty on the investment decisions." Energy Policy 101 (2017), 123-137.

Décamps, J.-P., T. Mariotti, and S. Villeneuve. "Irreversible investment in alternative projects." Economic Theory 28 (2006), 425-448.

Dias, M. A. G. "Valuation of exploration and production assets: an overview of real options models." Journal of Petroleum Science and Engineering 44 (2004), 93-114.

Dixit, A. "Optimal lay-up and scrapping decisions." Princeton University Working Paper (1988).

"Entry and exit decisions under uncertainty." Journal of Political Economy 97 (1989), 620-638.

—. "Choosing among alternative discrete investment projects under uncertainty." Economics Letters 41 (1993), 265-268.

Dixit, A. K., and R. S. Pindyck. Investment under Uncertainty. Princeton, NJ: Princeton University Press (1994).

Dockendorf, J. and D. Paxson. "Continuous rainbow options on commodity outputs: What is the value of switching facilities?" European Journal of Finance 19 (2013), 645-673.

Dumortier, J., N. Kaufman and D. Hayes. "Production and spatial distribution of switchgrass and miscanthus in the United States under uncertainty and sunk cost." Energy Economics 67 (2017), 300-314,

Fleten, S.-E, K. Maribu, and I. Wangensteen. "Optimal investment strategies in decentralized renewable power generation under uncertainty." Energy 32 (2007), 803-815.

Fleten, S.-E, A. Heggedal and Siddiqui, A. "Transmission capacity between Norway and Germany- a real option analysis." Journal of Energy Markets 4 (2011): 121-147. 
Guedes, J., and P. Santos. "Valuing an offshore oil exploration and production project through real options analysis." Energy Economics 60 (2016), 377-386.

Guerra, M., P. Kort, C. Nunes and C. Olivera. "Hysteresis due to irreversible exit: Addressng the option to mothball." Journal of Economic Dynamics \& Control 92 (2018): 69-83.

Hagspiel, V., K. Huisman, P. Kort and C. Nunes. "How to escape a declining market: capacity investment or exit?" European Journal of Operational Research 254 (2016): 40-50.

Insley, M. "Resource extraction with a carbon tax and regime switching pries: Exercising your option," Energy Economics 67 (2017), 1-16.

Kemp, A. G. "Economic and fiscal aspects of oil and gas field abandonment." Energy Policy 20 (1992), 4-19.

Kort, P. M., P. Murto, and G. Pawlina. "Uncertainty and stepwise investment" European Journal of Operational Research 202 (2010), 196-203.

Laughton, D. "The Management of Flexibility in the Upstream Petroleum Industry." The Energy Journal 19 (1998), 83-114.

Lavrutich, M.N. "Capacity choice under uncertainty in a duopoly with endogenerous exit." European Journal of Operational Research 258 (2017): 1033-1053.

Lukas, E., T.S. Spengler, S. Kupfer and K. Kieckhäfer. "When and how much to invest? Investment and capacity choice under product life cycle uncertainty." European Journal of Operational Research 260 (2017): 1305-1114.

Malchow-Møller, N., and B. J. Thorsen. "Repeated real options: Optimal investment behaviour and a good rule of thumb." Journal of Economic Dynamics and Control 29 (2005), 1025-1041.

McCormack, J., and G. Sick. "Valuing PUD reserves: A practical application of real option techniques." Journal of Applied Corporate Finance 13 (2001), 110-115.

Mossin, J. "An optimal policy for lay-up décisions." The Swedish Journal of Economics 70 (1968), 170-177.

Muehlenbachs, L. "Internalizing production externalities: A structural estimation of real options in the upstream oil and gas industry," PhD Dissertation, University of Maryland (2009).

Osmundsen, P., and R. Tveterås. "Decommissioning of petroleum installations - major policy issues." Energy Policy 31 (2003), 1579-1588.

Paddock, J. L., D. R. Siegel, and J. L. Smith. "Option valuation of claims on real assets: The case of offshore petroleum leases." Quarterly Journal of Economics 103 (1988), 479-508.

Parente, V., D. Ferreira, E. Moutinho dos Santos, and E. Luczynski. "Offshore decommissioning issues: Deductibility and transferability." Energy Policy 34 (2006), 19922001.

Paxson, D. "Multiple state property options." Journal of Real Estate Finance and Economics 30 (2005), 341-368.

Paxson, D., and H. Pinto. "Rivalry under price and quantity uncertainty." Review of Financial Economics 14 (2005), 209-224.

Pindyck, R. S. "The long-run evolution of energy prices." The Energy Journal 20 (1999), 127.

Preinreich, G. A. D. "The economic life of industrial equipment." Econometrica 8 (1940), 1244.

Siddiqui, A., and S.-E. Fleten. "How to proceed with competing alternative energy technologies: A real options analysis." Energy Economics 32 (2010), 817-830.

Siddiqui, A. S., and K. Maribu. "Investment and upgrade in distributed generation under uncertainty." Energy Economics 31 (2009), 25-37. 
Støre, K., V. Hagspiel, S.-E. Fleten, and C. Nunes. "Switching from Oil to Gas ProductionDecisions in a Field's Tail Production Phase." European Journal of Operational Research 271 (2018), 710-719.

Tourinho, O. A. F. "The option value of reserves of natural resources." In Research Program in Finance Working Papers: Graduate School of Business Administration, University of California at Berkeley (1979).

Trigeorgis, L. Real Options: Managerial Flexibility and Strategy in Resource Allocation. Cambridge, MA: The MIT Press (1996).

Truong, C., S. Trück and S. Mathew. "Managing risks from climate impacted hazards-The value of investment flexibility under uncertainty." European Journal of Operational Research, 269 (2018),132-145.

Wood, I. "UKCS maximising recovery review: Final report." In Report for Department of Energy \& Climate Change. London: UK Government Department of Energy \& Climate Change (2014). 